\title{
THE SURGICAL TREATMENT OF BLEEDING INTRACRANIAL ANEURYSMS*
}

\author{
BY \\ MURRAY A. FALCONER
}

From the Neurosurgical Unit, Dunedin Hospital, New Zealand, and the Guy's-Maudsley Neurosurgical Unit, London

\begin{tabular}{|c|c|c|c|}
\hline & I $\mathbf{N}$ & & \\
\hline & Page & & Page \\
\hline ASE Material & .. 154 & Aneurysms at the Bifurcation of the Internal & \\
\hline REOPERATIVE INVESTIGATIONS & .. 155 & Carotid Artery & 1 \\
\hline Matas Carotid Compression Test .. & .. 155 & Aneurysms of the Middle Cerebral Artery & 167 \\
\hline Carotid Arteriography & 155 & Experiences with Carotid Ligation & 167 \\
\hline Elective Surgical Procedures & .. 156 & Experiences with Intracranial Operation & 169 \\
\hline Carotid Ligation & 156 & Aneurysms of the Anterior Cerebral Artery & 170 \\
\hline Operative Exposure of the Intracranial & Internal & 1. Aneurysms of the proximal portion of the & \\
\hline Carotid Artery and its Branches & 157 & Artery & 170 \\
\hline Problems With ANEURYSMS IN SPECIAL SITE & ES $\quad . .160$ & 2. Aneurysms Involving the Anterior Com- & \\
\hline ortion of the Internal & l Carotid 160 & $\begin{array}{c}\text { municating Artery } \\
\text { Experiences with Carotid Ligation }\end{array}$ & $\begin{array}{l}173 \\
174\end{array}$ \\
\hline Experiences with Primary Internal & $\because$ Carotid & $\begin{array}{l}\text { Experiences with an Intracranial Attack } \\
\text { 3. }\end{array}$ & \\
\hline $\begin{array}{cccc}\text { Experiences } & \text { with } & \text { Primary } & . . \\
\text { Ligation } & . & .\end{array}$ & $\begin{array}{lll} & \text { Carotid } \\
\ldots & \ldots & 161\end{array}$ & $\begin{array}{c}\text { Artery } \\
\text { Aneurysms of the Vertebral, Basilar, and Posterior }\end{array}$ & 1 \\
\hline Need for Secondary Internal Carotid & & Cerebral Arteries .. & 180 \\
\hline followin Primaru Common Carotid & ion 162 & ISCUSSION & \\
\hline Need for a Supplementary & tracranial & SUMMARY & 185 \\
\hline Attack & .. 162 & REFERENCES & 185 \\
\hline
\end{tabular}

Since Symonds in 1923 and 1924 drew attention to the relationship between subarachnoid haemorrhage and leaking intracranial aneurysms, "interest has been centred in the aetiology of this condition rather than in its treatment. Customarily spontaneous subarachnoid" haemorrhage is treated by rest and quiet. Yet with such conservative management the mortality rate in most general hospitals ranges between 50 and $60 \%$, while only 15 to $30 \%$ of sufferers make a satisfactory recovery (Table I). Spontaneous subarachnoid haemorrhage is thus a deadly and treacherous condition, and one which offers a challenge to surgery. Recently I (1950) drew attention to the possibilities of surgical treatment. In this particular paper I wish to consider

* Presented at the combined meeting of the Society of British Neurological Surgeons and the Sociedad Luso-Española de Neurocirurgia at Madrid on April 28, 1951. in greater detail the operative management of leaking intracranial aneurysms, for these are lesions responsible for at least three-quarters of the cases of subarachnoid haemorrhage (Richardson and Hyland, 1941 ; Magee, 1943 ; also personal experience).

Several surgeons have reported their experiences with leaking intracranial aneurysms, but few have recorded more than two or three cases. Two main operative approaches have been tried-carotid ligation and a direct intracranial exposure of the aneurysm. Carotid ligation is efficacious when the aneurysm is situated on the internal carotid artery itself, but is of less certain value when the aneurysm is situated on the circle of Willis or on one of its distal branches, for it then becomes supplied with blood from the opposite carotid artery, and may once more cause symptoms. Furthermore, in cases of intracranial aneurysm 
where there has been recent subarachnoid bleeding, it would seem that carotid ligation carries an enhanced risk. Thus Schorstein (1940), in reporting the collective experience of the Society of British Neurological Surgeons, recorded five deaths in nine cases of bleeding aneurysm treated by carotid ligation (presumably internal carotid artery) as opposed to three deaths in 22 cases of aneurysm which did not bleed. Hermann, Obrador, and Dott (1937) recorded a $25 \%$ mortality rate in 12 cases of leaking aneurysm treated by internal carotid ligation, and Krayenbühl (1946) a 30\% mortality rate in 20 cases. Rogers (1949), however, performed common carotid ligation in six cases with only one death.

An intracranial exposure of the aneurysm, although hazardous, permits of more precise treatment. The local measures available once the aneurysm has been exposed range from wrapping hammered muscles around it (Dott, 1933), to incising the aneurysm and packing muscle into its interior (McConnell, 1937), clipping the neck of the aneurysm (Dandy, 1938), trapping the aneurysm by occluding the artery on either side of its neck (Fincher, 1939), to shrivelling the aneurysmal sac with diathermy (Dandy, 1944). At least three cases are recorded in which the aneurysm has been excised (Cone, 1939 ; Dandy, 1944 ; Elvidge and Feindel, 1950). However, although the various surgeons listed above, and also Tönnis (1936), List and Hodges (1946), Jefferson (1947), Swain (1948), Murphy (1949), Elvidge and Feindel (1950), and Jaeger (1950), have each described cases treated by an intracranial attack, it is not yet possible to assess statistically the hazards of direct surgical intervention, because only Dandy and Jaeger have recorded more than an occasional case. Dandy (1944), encountered at operation 36 cases of aneurysm, 30 of which he treated by various local measures with nine deaths, but few of his cases were complicated by subarachnoid bleeding. Jaeger (1950) has recently reported 20 cases of leaking aneurysm situated on the intracranial internal carotid artery, which were submitted to a direct intracranial attack with five deaths.

It seems that most surgeons who have operated for intracranial aneurysm, either by carotid ligation or by a direct attack, have experienced mortality rates ranging from about 25 to $50 \%$, and consequently have usually limited their interventions to patients gravely ill with recurrent bleeding, and considered past hope of spontaneous recovery. My own view, however, is that the prognosis of subarachnoid haemorrhage can be improved so much that all cases should be investigated and treated as a routine in a surgical manner.

\section{CASE MATERIAL}

This report is based mainly on $\mathbf{5 0}$ cases of leaking aneurysm operated on by myself or by my former associate, Mr. Anthony James, in the Neurosurgical Unit of the Dunedin Hospital, New Zealand, between May, 1946 and June, 1950. Both carotid ligature and an intracranial attack were employed, either singly or in combination. Many of the patients were gravely ill, and as a group they must be regarded as having a particularly serious outlook had they continued on conservative management. Of the 50 patients, 33 made good recoveries, eight recovered with an appreciable disability (total recovery rate, $82 \%$ ) and only nine died (mortality rate, $18 \%$ ). Twenty-four of the patients were 40 years of age or under, and of these only two died.

These 50 cases of leaking aneurysm were recognized as a result of arteriography or operation in 69 consecutive cases of recent subarachnoid haemorrhage admitted to the Neurosurgical Unit of the Dunedin Hospital from various hospitals in New Zealand. Half of these cases had experienced more than one attack of bleeding, and most were referred within less than a week of the last attack. The symptoms shown were similar to those usually reported in spontaneous subarachnoid haemorrhage. Arteriography was performed in all except the first two cases (both verified by operation), and at the time of this investigation the lumbar cerebrospinal fluid was still bloodstained or xanthochromic in all but seven cases. In only six cases was arteriography undertaken later than two weeks from the onset of the last attack of bleeding, for our policy was to perform this examination as soon as could be conveniently arranged after the patient's admission. The findings in the total group of 69 cases were as follows :-

(A) Intracranial aneurysm (52 demonstrated examples) $\quad . \quad$.

(B) Arteriovenous malformations $\quad \ldots \quad$.

(C) Intracerebral haemorrhage from a leaking

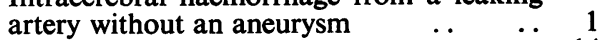

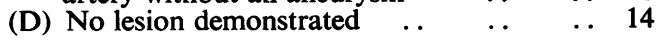

$$
\begin{array}{lllll}
\text { Total } \ldots & \ldots & \ldots & \ldots & \mathbf{6 9}
\end{array}
$$

In addition to the nine cases in Group $A$ that died, two cases in the last group died and subsequently were examined at necropsy. All cases in Groups B and C, however, recovered after operation. The mortality rate for the whole series of 69 cases was therefore $16 \%$.

Of the 50 cases, 22 were men and 28 women. Their ages ranged from 19 to 67 years, with three patients in the second decade of life, 10 in the third 11 in the fourth, 16 in the fifth, seven in the sixth 
and three in the seventh decade. In three female cases subarachnoid bleeding was associated with pregnancy, and either preceded or followed an abortion or parturition by a few days; all three patients survived. Two cases were shown to have multiple aneurysms (two each, making 52 demonstrated aneurysms in 50 patients). The whole group of 50 cases can be conveniently divided according to the site of the bleeding aneurysm as follows :-

Aneurysms of the intracranial portion of the internal carotid artery ..

Cases

Aneurysms at the bifurcation of the internal carotid artery ( 5 demonstrated aneurysms)..

Aneurysms of the middle cerebral artery (11 demonstrated aneurysms) . . $\quad . \quad \quad \ldots \quad 10$

Aneurysms of the anterior cerebral artery $\quad \ldots \quad 17$
(a) on proximal part of artery
2 cases
(b) in region of anterior com- municating artery .. ..
11 cases
(c) on distal part of artery ..
4 cases

$$
\begin{array}{lllll}
\text { Total } & . & \ldots & & \\
50 &
\end{array}
$$

\section{PREOPERATIVE INVESTIGATIONS}

In each case as full a neurological examination as possible was carried out, particular attention being paid to the presence or absence of a third cranial nerve palsy or of a subhyaloid retinal haemorrhage, for these were found to be important lateralizing signs. A hemiparesis, however, was of uncertain value, being sometimes on the same side and sometimes on the opposite side as the aneurysm, while inequalities of the pupils too were often misleading. (A detailed consideration of the neurological signs is outside the scope of this paper.) The diagnosis of subarachnoid haemorrhage was confirmed in all cases by lumbar puncture. In addition the Matas digital compression test and carotid arteriography were routine preliminary investigations.

\section{Matas Carotid Compression Test}

Dandy (1944) relied on the Matas carotid compression test for indicating the state of the collateral blood-flow from the opposite carotid artery through the circle of Willis, and he considered that, if a patient could withstand digital compression of a carotid artery in the neck for ten minutes, then the internal carotid artery on that side could be safely ligated without risk of hemiplegia. However, I have now seen several cases in which this test seemed to be borne well, but subsequently carotid ligation was not tolerated and the ligature had to be released. Probably the explanation is that it is difficult, if not virtually impossible, to make certain that the common carotid artery is completely occluded throughout the test. As a routine precaution we always have a second observer palpating the superficial temporal artery continuously to ensure that it does not pulsate while the examiner is compressing the carotid artery in the neck. Even this precaution is not sufficient, for we have noticed after partial ligations of the common carotid artery that the superficial temporal pulse may disappear, even though the common carotid artery is still partly open.. Thus a negative Matas test must be accepted with reserve. A positive result, seen when digital compression of a carotid artery is not tolerated, certainly suggests an anomaly of the circle of Willis, and points to the need for caution in treatment.

Incidentally the Matas test may be of value in indicating the side of the aneurysm, for compression of the appropriate carotid artery will often ease the pain originating in an aneurysm.

\section{Carotid Arteriography}

The use of carotid arteriography in subarachnoid haemorrhage was pioneered by Moniz (1934), Dott (1933), and Jefferson (1937). In most of our cases the technique employed was that of Moniz (1933 and 1934). Under local analgesia each common carotid artery is exposed aseptically, while the patient lies in position on the radiographic table. Two small transverse incisions are made through the skin, one a little above the inner end of each clavicle, and access to the carotid sheath is obtained by separating the two heads of the sternomastoid muscle. The common carotid artery is then exposed by opening the carotid sheath and is often injected as it lies in situ. Sometimes, however, a tape is first placed in position around the artery to steady it. In either event 8 to $10 \mathrm{ml}$. of the contrast medium are injected at a time, and films are usually exposed for both the arterial and venous phases of filling. Each artery is usually injected twice, once for a lateral $x$-ray projection and once for an anteroposterior projection. At the conclusion of the radiological studies the common carotid artery is already exposed, ready for ligation, if this should be indicated.

The contrast medium 'generally used was $35 \%$ "diodone" compound solution, but in a few early cases " thorotrast" was used instead. Thorotrast gives clear-cut pictures with very little disturbance to the patient, but it is radioactive and is not excreted. Diodone solution gives almost as good visualization, and has the advantage that it is promptly excreted in the urine, but it may cause temporary spasm of cerebral vessels with the production of severe headache followed immediately by a transient hemiplegia. Often we 
noted that the cerebral vessels close to an aneurysm might appear attenuated and somewhat irregular, and in the earlier stages of our experience we deduced this to be evidence of a local protective arterial spasm. We are not certain of this interpretation, however, since we performed arteriography with diodone solution and with thorotrast in a case on successive days, and observed arterial spasm with the first medium, whereas the vessels appeared entirely normal with the second. Undoubtedly diodone solutions themselves often cause spasm.

Dandy (1944) deprecated arteriography, mainly because of a fear of cerebral thromboses when thorotrast was used, and, if clinical features were present indicating the site of the aneurysm, he felt that the circle of Willis should be explored on that side without this diagnostic aid. Indeed in only four of Dandy's cases was arteriography performed, and then only because the examination had been made elsewhere before the patient was referred to Dandy. As might be expected, Dandy's records contain protocols of several cases of aneurysm, which had no localizing signs and were not located until they came to necropsy. Dandy, however, did concede that further experience might prove arteriography advisable as a routine procedure, because of the precise information it could give as to the site and size of the aneurysm, as well as to the patency of the collateral vessels. Moreover, we have not seen the thrombotic complications of thorotrast which Dandy feared.

There are several reasons why arteriography is desirable as a routine preliminary in the surgical investigation of subarachnoid haemorrhage. First, it is necessary to establish the nature, size, and site of a bleeding lesion-whether it is an aneurysm, arteriovenous malformation, vascular tumour, or other lesion-as often in subarachnoid haemorrhage there are no localizing or lateralizing neurological signs. Secondly, it may disclose that a massive intracerebral clot is present in addition to the subarachnoid haemorrhage, and an essential part of the operative management then is the prompt evacuation of the clot. Thirdly, arteriography may give information concerning the presence of anomalies in the circle of Willis and the state of the collateral circulation. A useful manoeuvre in testing the collateral circulation and in determining whether carotid ligation will prove efficacious, is to occlude temporarily one common carotid artery with a Crile's clamp and then inject the other with contrast medium. Finally arteriography may disclose the presence of two or more aneurysms in one patient ; this happened twice in my series.

Recently with increasing experience of percutaneous arteriography, we have resorted more and more to this method. But when the patient is gravely ill or has a stout neck and it is desirable to obviate any undue straining lest a recurrence of bleeding occur during the prodecure, we still prefer the " open" method of Moniz.

\section{ELECTIVE SURGICAL PROCEDURES}

If the aneurysm can be controlled surgically this seems an obvious advantage, and we have come to attempt surgical intervention in nearly all cases. Two different approaches can be used, carotid ligation and an intracranial exposure. They may be used either singly or together, and the choice in each case depends largely upon the situation of the aneurysm. Some general points will now be considered about each, before discussing their use according to the various sites at which an aneurysm may occur.

\section{Carotid Ligation}

Ligation of either the common or internal carotid artery was generally performed under local analgesia, a heavy silk ligature being drawn around the artery and tied with the vessel still in continuity. In our earlier cases each artery was tied tightly in a single stage, but in the later cases the common carotid artery was often tied in two or more stages. At the first stage the lumen of the artery was narrowed by a third or a half. Two or three days later the wound was reopened, and the artery occluded completely by a second ligature placed around it at the same level as the first. Our experience indicates that ligation of the common carotid artery in stages carries little risk of a subsequent hemiplegia (see later), and can be performed when a period of trial occlusion shows that a single-stage ligation of the artery would cause symptoms. Even the method of ligation recommended by Rogers (1944 and 1947), whereby the common carotid artery is tied tightly between ligatures and divided between them, is not without risks, and in the only cases in which we tried it, a case of aneurysm of the middle cerebral artery, a hemiplegia followed.

As regards exposure, the same Moniz approach employed for common carotid arteriography served also for ligation of that vessel. The internal carotid artery was always exposed by an oblique incision placed along the upper border of the sternomastoid muscle. At the first stage of ligation the adequacy of the collateral circulation through the circle of Willis was first tested by temporarily compressing the vessel with a Crile's clamp. If this compression was tolerated for a period of about half an hour, then the artery was usually tied forthwith. If, 
however, the compression produced signs or symptoms of cerebral anoxaemia (and generally these appeared within a few minutes), then either the first stage of partial narrowing of the artery was proceeded with warily, or depending upon the situation of the aneurysm, an intracranial exposure would be undertaken without a preliminary carotid ligation.

We placed our chief reliance in avoiding a postligation hemiplegia upon this trial period of occlusion with a Crile's clamp. Also we often tested the adequacy of the collateral circulation by performing arteriography of the opposite carotid artery after the ipsilateral vessel had been occluded. In two instances in which a post-ligation hemiplegia appeared within a few hours of ligation, the neck wound was promptly reopened and the ligature released, with, however, recovery of the hemiplegia in only one case. We have not tried Rogers' (1944) method of simultaneously performing electroencephalography during the trial period of compression of the common carotid artery and observing whether the normal cerebral rhythm persists or is altered by cerebral anoxia. In one of my recent cases this method had been tried in another hospital, where it was found that compression of the common carotid artery continued for only 50 seconds suppressed the cerebral rhythm. However, subsequently we were able to perform ligation of the artery successfully in two stages. Neither have we had personal experience of the method of Sweet, Sarnoff, and Bakay (1950) whereby the pressure within the distal part of the artery is measured and the effect of occlusion noted. This method probably merits further trials.

\section{Operative Exposure of the Intracranial Internal Carotid Artery and its Branches}

If need be it is possible to expose at operation not only the whole course of the intracranial internal carotid artery, but also a large part of the anterior and middle cerebral arteries as well. A unilateral frontal craniotomy of the type used for a " pituitary " exposure is turned on the appropriate side, usually under general anaesthesia (Fig. 1). When the anterior cerebral artery is to be exposed, the anterior limb of the bone flap should be fashioned so as to reveal 4 or $5 \mathrm{~cm}$. of the superior longitudinal sinus immediately posterior to the frontal air sinuses, but in other cases the bone flap may fall a little short of the sinus. Next, in all cases, the lateral part of the dural envelope covering the frontal lobe is elevated off the orbital plate of the frontal bone, and is incised immediately in front of the sphenoidal ridge. As this is done, cerebrospinal fluid usually seeps through from the inner part of the Sylvian fissure, and, as the fluid is aspirated, the frontal lobe is raised off the anterior cranial fossa. Before long the optic nerve is exposed, and after the arachnoidal layer in front of this has been incised, cerebrospinal fluid flows more readily from the cisterns, thus facilitating the elevation of the brain from the base of the skull.

The intracranial portion of the internal carotid artery is located immediately behind and slightly lateral to the optic nerve (Fig. 2). To expose it properly the arachnoidal layer in front of it has to be incised upwards. Useful tools for this purpose are a fine-bore metal sucker to keep the field dry and a blunt neurosurgical hook with which to apply diathermy current to the various arachnoidal strands. Should small veins or even small arterial branches cross the line of the main artery or start bleeding, they can be caught in the mouth of the metal sucker and coagulated with diathermy. In this way the internal carotid artery is exposed to its bifurcation into the anterior and middle cerebral arteries, and this stage should be completed before the further exposure of the middle or anterior cerebral arteries is begun.

If the middle cerebral artery is to be exposed, the fissure of Sylvius must first be opened up (Fig. 3). To do this the arachnoidal layer covering the fissure must be divided, and then the opposing surfaces of the frontal and temporal opercula are gently separated. The most convenient place at which to start this process is on the convexity of the hemisphere just behind the Sylvian point, and from this spot the incision of the arachnoid is carried forwards to where the internal carotid artery has already been exposed. In my experience this incision has always run just above and parallel to the Sylvian veins, so that when the fissure is opened up these vessels are retracted downwards with the temporal lobe, and no sizeable vessels, apart from a few minute venous twigs which span the fissure, need be divided. The middle cerebral artery is located in the depth of the fissure, and can be followed forwards to its origin. If it has to be exposed in its more posterior course over the island of Reil, the arachnoidal incision over the Sylvian fissure has first to be extended backwards.

The exposure of the anterior cerebral artery is not difficult. In the first part of its course the artery passes inwards from the bifurcation above the optic nerve to the inferior aspect of the genu of the corpus callosum where it joins its fellow of the opposite side and the two are connected by the short anterior communicating artery. By elevating the inferior surface of the frontal lobe medial to the internal carotid artery, it is generally possible to 

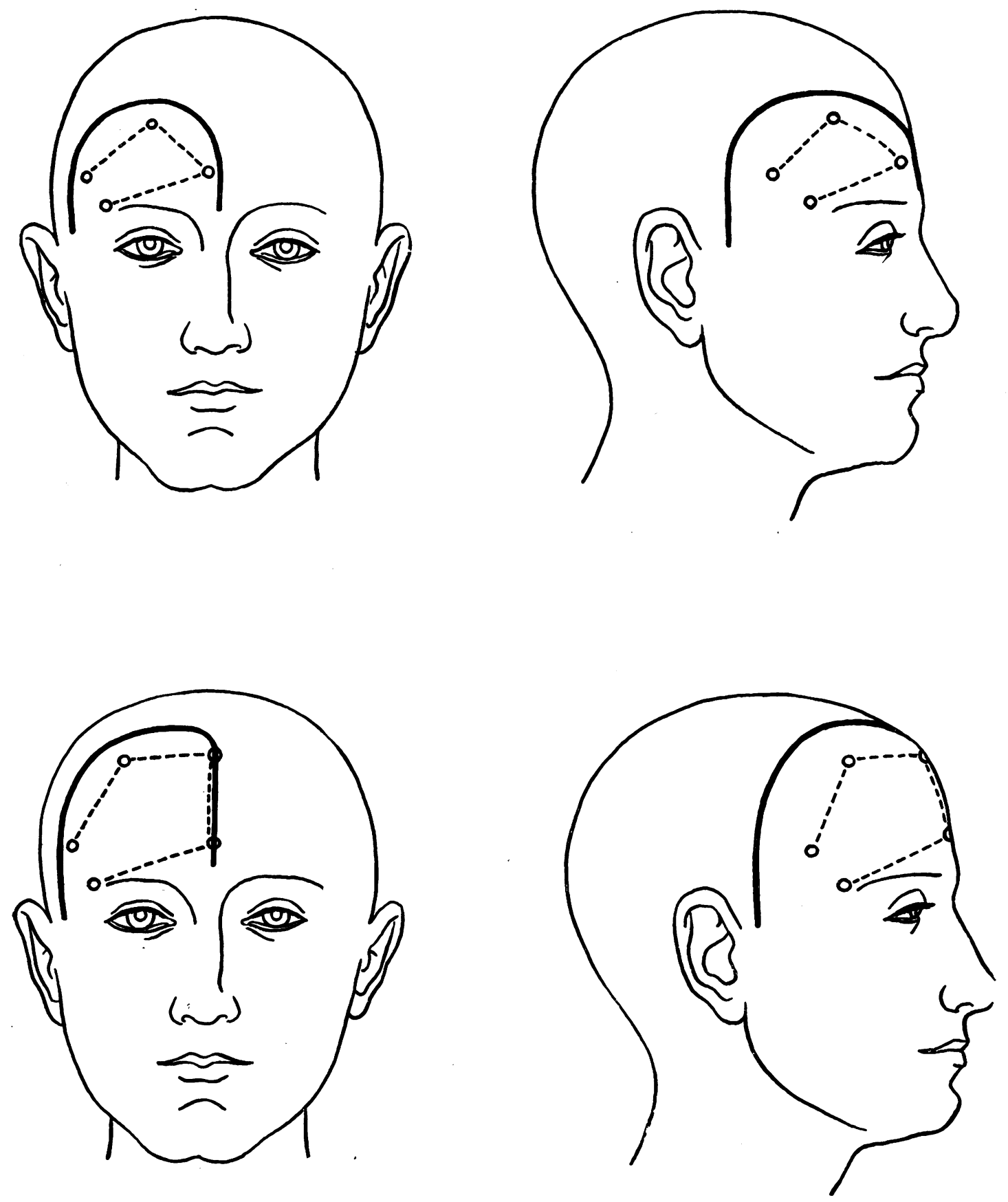

FIG. 1.-(Left) above, siting of scalp incision and of bone flap to expose intracranial internal carotid artery and middle cerebral artery. Below, sitings when anterior cerebral artery is to be exposed. 


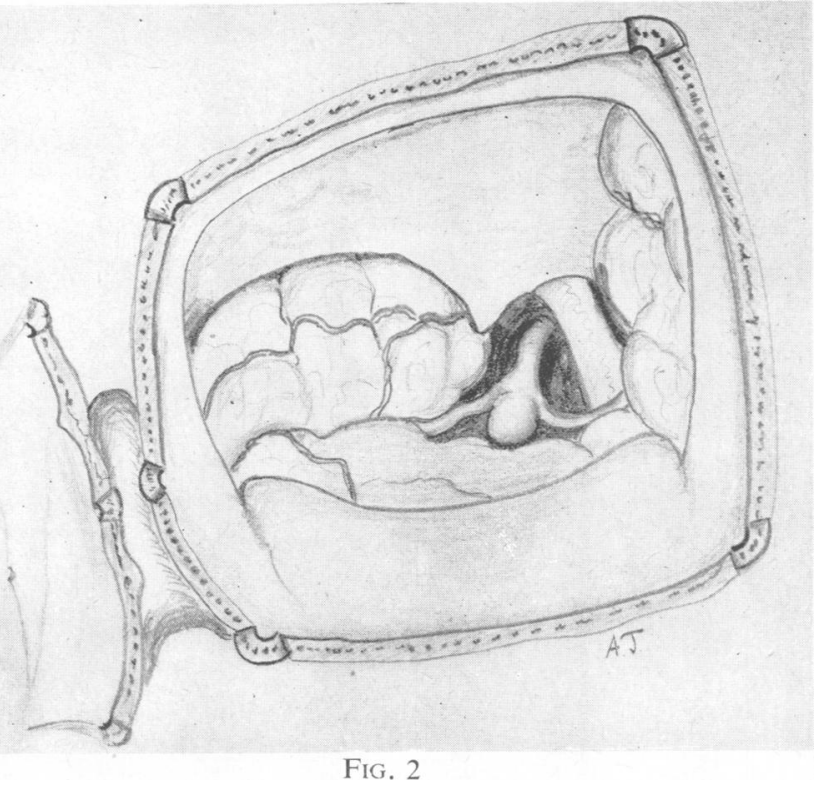

FIG. 2.-Operative sketch showing aneurysm at bifurcation of left internal carotid artery. Note relationship of internal carotid artery and its middle and anterior cerebral branches to the left optic nerve.

FIG. 3.-Operative sketch showing aneurysm of left middle cerebral artery displayed after the fissure of Sylvius has been opened up.

expose the anterior cerebral artery as far as the anterior communicating artery, and sometimes even for a centimetre or so beyond this point to the summit of the genu. If the anterior cerebral artery has then to be followed further, the operative approach has to be changed from this subfrontal one to the superior one (Fig. 4). After any veins passing from the pole and superior margin of the frontal lobe to the superior longitudinal sinus have been divided, the mesial surface of the frontal lobe is retracted from off the falx and its fellow of the opposite side. In this way the two anterior cerebral arteries, right and left, are revealed as they run together over the corpus callosum.

Using these intracranial approaches it should be possible to expose practically every aneurysm on the intracranial course of the internal carotid artery or on its anterior and middle cerebral branches. As Richardson and Hyland (1941) and also Robertson (1949) have pointed out, many cases of aneurysm, particularly of the middle and anterior cerebral arteries, give rise to massive intracerebral haemorrhage within the adjacent parts of the brain in addition to subarachnoid haemorrhage. In such cases the brain may appear "tight" when the craniotomy flap is turned, and adequate exposure of the various main arteries is often not possible until the space-occupying lesion has been relieved by evacuation of the intracerebral clot. Many aneurysms, however, even when there has been recent subarachnoid bleeding, will not show any direct evidence of leaking when they are exposed. Occasionally, however, a little clot is seen alongside the aneurysm or perhaps some haemosiderin staining of the adjacent cortex, while sometimes the clot of an intramural haemorrhage can be seen in its wall. In five instances the aneurysm bled while it was under view, but only twice was the bleeding torrential. I have, however, not seen at operation

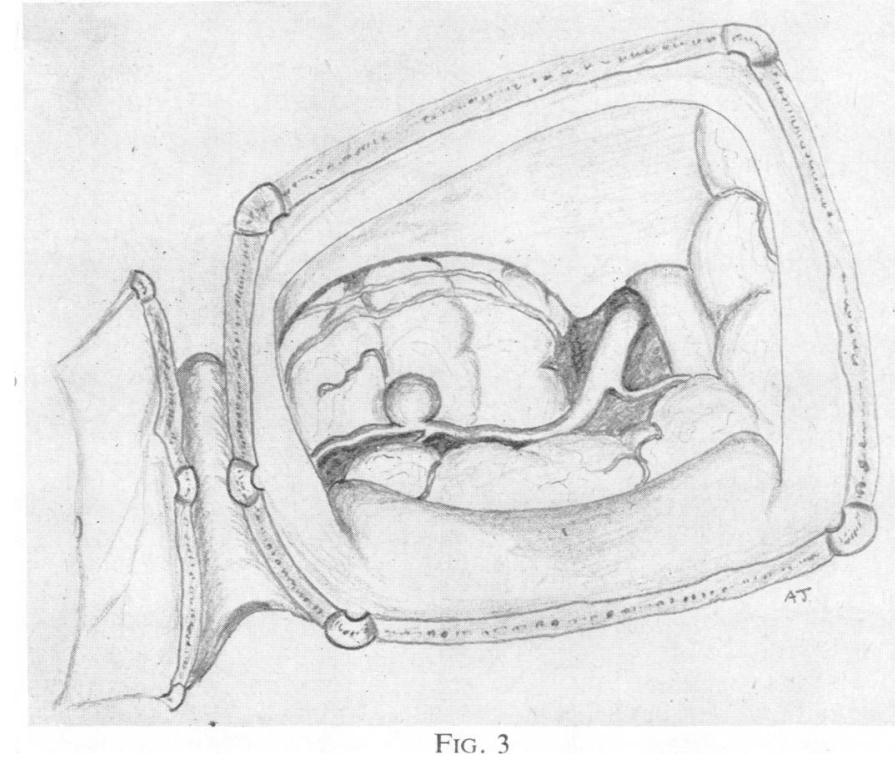




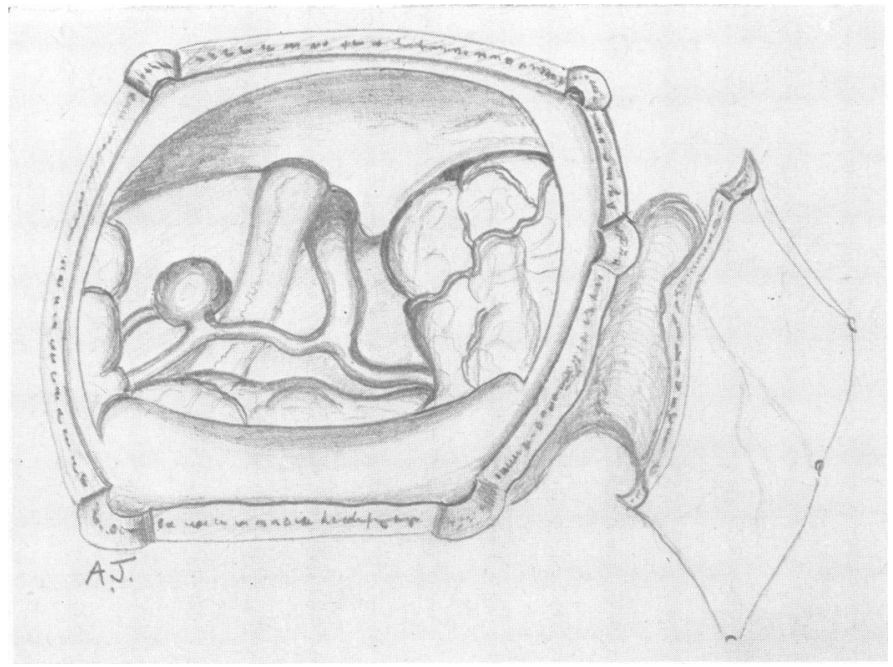

FIG. 4.-Operative sketch showing aneurysm of anterior communicating artery exposed by combination of subfrontal and vertical approaches from the right side.

the basal cisterns packed with solid clot as is so often seen at necropsy. Presumably subarachnoid clotting of such severity is a terminal phenomenon which causes death so rapidly that surgical intervention is precluded.

\section{PROBLEMS WITH ANEURYSMS IN SPECIAL SITES}

\section{In the Intracranial Portion of the Internal Carotid Artery}

This is one of the largest subgroups of intracranial aneurysms. There were 19 examples in our 50 patients, and they were treated surgically with 13 good recoveries, four recoveries with disability, and two deaths. Our experience indicates that, although carotid ligation is the sheet-anchor of treatment for this subgroup, wherever practicable this measure should be followed by an intracranial clipping of the internal carotid artery immediately above the aneurysm. Thus the aneurysm is "trapped" or permanently excluded from the circulation, as the remaining source of supply via the ophthalmic artery is of negligible importance.

Dott (1933) was the first to operate successfully on an aneurysm of this group, which he treated by wrapping with muscle. Subsequently his patient lived for 11 years without cerebral symptoms and then died of another cause (Dott, 1948). In 1939, Fincher reported the first successful trapping of an aneurysm in this situation, and since then both Dandy (1944) and Jaeger (1950) have added their experiences of the intracranial approach. Dandy operated on 13 cases with three deaths, but in only three of his cases had there been recent subarachnoid bleeding. On three occasions he clipped the neck of the aneurysmal sac, and in the remaining 10 cases he either trapped the aneurysm or coagulated with diathermy the portion of the internal carotid artery which bore it. Jaeger more recently has reported treating 20 cases by a direct attack with five deaths. In eight cases he clipped or ligated the neck of the aneurysm; in eight cases he trapped the aneurysm; and in two cases he wrapped it with a laver of "cotton". Other surgeons have treated these aneurysms, particularly by carotid ligation, but it is difficult to tell from their publications the numbers of cases treated and the results.

Aneurysms in this particular situation have certain characteristic arteriographic and clinical features. Almost always they arise either just above or just below the posterior communicating artery in the angle between that artery and the parent internal carotid artery. Consequently, in the arteriograms they are seen to project posteriorly or postero-laterally from the internal carotid artery, and are displayed to best advantage in the lateral arteriograms, whereas in antero-posterior views they may be superimposed on the carotid siphon (Figs. 5-9). Some writers have interpreted the arteriographic appearances as those of an aneurysm of the posterior communicating artery, but Dandy was insistent from his post-mortem observations that they are really aneurysms of the internal carotid artery. From the clinical viewpoint these aneurysms are immediately above the third cranial nerve where it passes forwards over the small triangular area of dura immediately lateral to the clinoid processes, and consequently a third cranial nerve palsy is a common feature (Albright, 1929 ; Jefferson, 1947). Indeed a third cranial nerve 
palsy, either partial or complete, was noted in 13 of our 19 cases.

Experiences with Primary Internal Carotid Ligation.-Being on the internal carotid artery a few millimetres or more below the circle of Willis, these aneurysms are readily treated by carotid ligation. Several methods of carotid ligation were tried before stage-ligation of the common carotid artery, followed later by ligation of the internal carotid artery, was adopted as the routine sequence. At first, primary ligation of the internal carotid artery was tried and was carried out in eight patients, including one who had been first explored intracranially. In seven patients the artery was tied tightly in a single stage, and in the remaining one the artery was only partially occluded. The case that had been explored intracranially died, but the remaining seven survived, although three were left with a persistent hemiplegia. Of the four cases that made excellent recoveries, one on admission was blind with bilateral subhyaloid ocular haemorrhage, and subsequently after weeks of blindness his vision recovered completely.

In the first of the three patients who survived with a persistent hemiplegia, the weakness appeared rapidly on the third post-operative day in a man of 67 years, who had been given prophylactic heparin therapy in the first 36 hours. In the second, a young woman aged 19 years, intracranial bleeding recurred immediately following arteriography and caused rapid loss of consciousness ; carotid ligation was carried out within a few minutes and hemiplegia was noticed within a few hours. In the third case, a woman of 47 years, whose artery was only partially occluded, the hemiplegia appeared within eight hours and was not relieved by prompt removal of the ligature; indeed when the ligature was released the artery, judging from palpation, was already thrombosed.

In the case which died (the second patient in the series on whom no preliminary arteriography was performed) the aneurysm was first explored intracranially and, when it was actually being exposed, it burst, resulting in a torrential haemorrhage which was controlled with difficulty by packing hammered muscle around the aneurysm. After shock from blood loss had been corrected by blood transfusion, the internal carotid artery was ligated in the neck. On the fourth day a contralateral hemiplegia appeared and the patient became unrousable. Death occurred on the eighth day, and at necropsy the internal carotid artery was found to be thrombosed up to the bifurcation, while extensive infarction had occurred in the brain in the territory supplied by the middle cerebral artery.
We concluded from this and from the other three cases that developed hemiplegia, that primary ligation of the internal carotid artery involves considerable risk of persistent hemiplegia developing, as has been stressed on a number of occasions by Rogers (1947 and 1949). The hemiplegia particularly affects the face and arm, the leg tending to escape. Subsequently we tried to avoid this complication by first ligating the common carotid artery, followed later by ligation of the internal carotid artery.

Experiences with Primary Common Carotid Ligation.-In our earlier cases the internal carotid artery was exposed for arteriography, and consequently this artery was then chosen for ligation. However, when the Moniz approach was adopted the common carotid artery became readily available instead. In two or three cases we found occluding the common carotid artery with a Crile's clamp preparatory to ligation produced cerebral anoxia signs within a few minutes. These signs, however, did not occur when the artery was only partially narrowed. It was from such cases that we came to develop the method of stage-ligation of the common carotid artery.

The technique of stage-ligation has already been described. Ten patients were treated in this way without any untoward complications (although one of the ten subsequently developed a delayed hemiplegia following intracranial tapping). Included in these ten patients were two who did not stand the trial occlusion of the common carotid artery with a Crile's clamp, yet they both tolerated partial narrowing progressing to complete occlusion in three stages. An eleventh patient (the remaining patient intended for treatment by stage-ligation) died two days after the first stage of only partial occlusion of the artery ; at necropsy both common carotid arteries were found to be thrombosed. Although only 24 years of age, his carotid vessels were markedly atheromatous, and clotting had evidently originated in each artery at the site of arterial puncture. This case is very exceptional, and apart from it no case treated by stage-ligation of the common carotid artery developed a postligation hemiplegia, whereas four out of eight cases treated by primary internal carotid ligation did. Primary common carotid ligation thus seems safer than primary internal carotid ligation, a conclusion which has already been stressed by Rogers (1949).

It is of course unnecessary to ligate the common carotid artery always in two stages, and often a complete ligation in a single stage will suffice. This is especially the case when arteriography of the opposite carotid artery, performed while the 


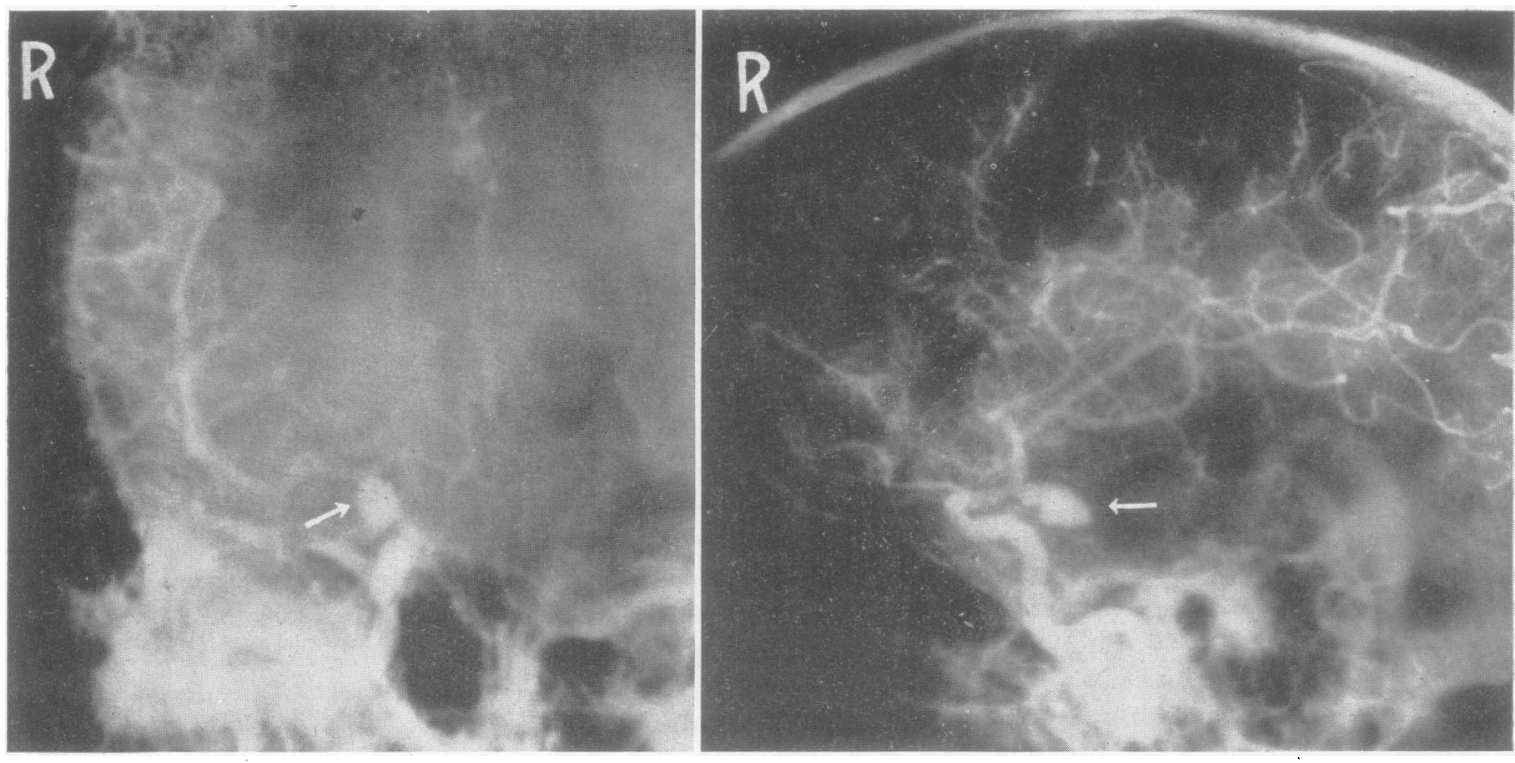

FIG. 5.-Anteroposterior and lateral arteriograms showing moderate-sized aneurysm (arrow) of intracranial internal carotid artery.

ipsilateral carotid is compressed, has disclosed an adequate collateral circulation through the circle of Willis. Failing such evidence, and especially in elderly people, it is wiser to play for safety and proceed slowly with ligation in two stages.

Need for Secondary Internal Carotid Ligation.Common carotid ligation alone is not sufficient for many aneurysms of the intracranial portion of the internal carotid artery, but should always be followed by ligation of the internal carotid artery. Several of our observations indicate this. One patient, two weeks after stage-ligation of the common carotid artery had been concluded, developed a complete third-nerve palsy and had a fresh attack of subarachnoid bleeding. The internal carotid artery was then explored intracranially and a silver clip was placed across the artery just above the aneurysm. Immediately the sac of the aneurysm burst, and a brisk stream of blood welled up. This was controlled only when the lowest part of the intracranial internal carotid artery was clamped with an artery forceps. While the forceps was still in position, the internal carotid artery was exposed in the neck and ligated, after which the artery forceps was safely removed. Although the common carotid artery had been occluded previously, definite arterial pulsations were noted in the internal and external carotid arteries in the neck, although they were of lesser amplitude than normal. In a second patient, in whom the internal carotid artery was clipped intracranially above the aneurysm a few days after the common carotid artery had been tied in the neck, we had a similar experience of an aneurysmal sac bursting. These two cases demonstrate the power that can develop in the collateral circulation down the external carotid artery into the internal carotid artery, and indicate why common carotid ligation should be followed by internal carotid ligation*.

Need for Supplementary Intracranial Attack.Probably in most cases ligation of the internal carotid artery (performed preferably following a preliminary common carotid ligation) is sufficient to give permanent relief. However, an aneurysm of this particular subgroup may continue to fill by reflux from the circle of Willis and may again cause trouble. Various observations suggest this.

Fairly often when performing arteriography of the contralateral carotid artery after the ipsilateral artery has been occluded, we have observed the contrast medium fill not only the anterior and middle cerebral arteries on both sides, but also the terminal portion of the intracranial internal carotid artery on the opposite side. This indicates that blood may reflux into the internal carotid artery from the

* Recently I have encountered a case in which aphasia together with weakness of the face and arm supervened 16 hours after a secondary internal carotid ligation. The ligature was released within two hours, and the artery did not seem thrombosed. Presumably two hours, and the artery did not seem thrombosed. Presumably
arterial spasm had occurred. Recovery is proceeding gradually. arterial spasm had occurred. Recovery is proceeding gradually. 


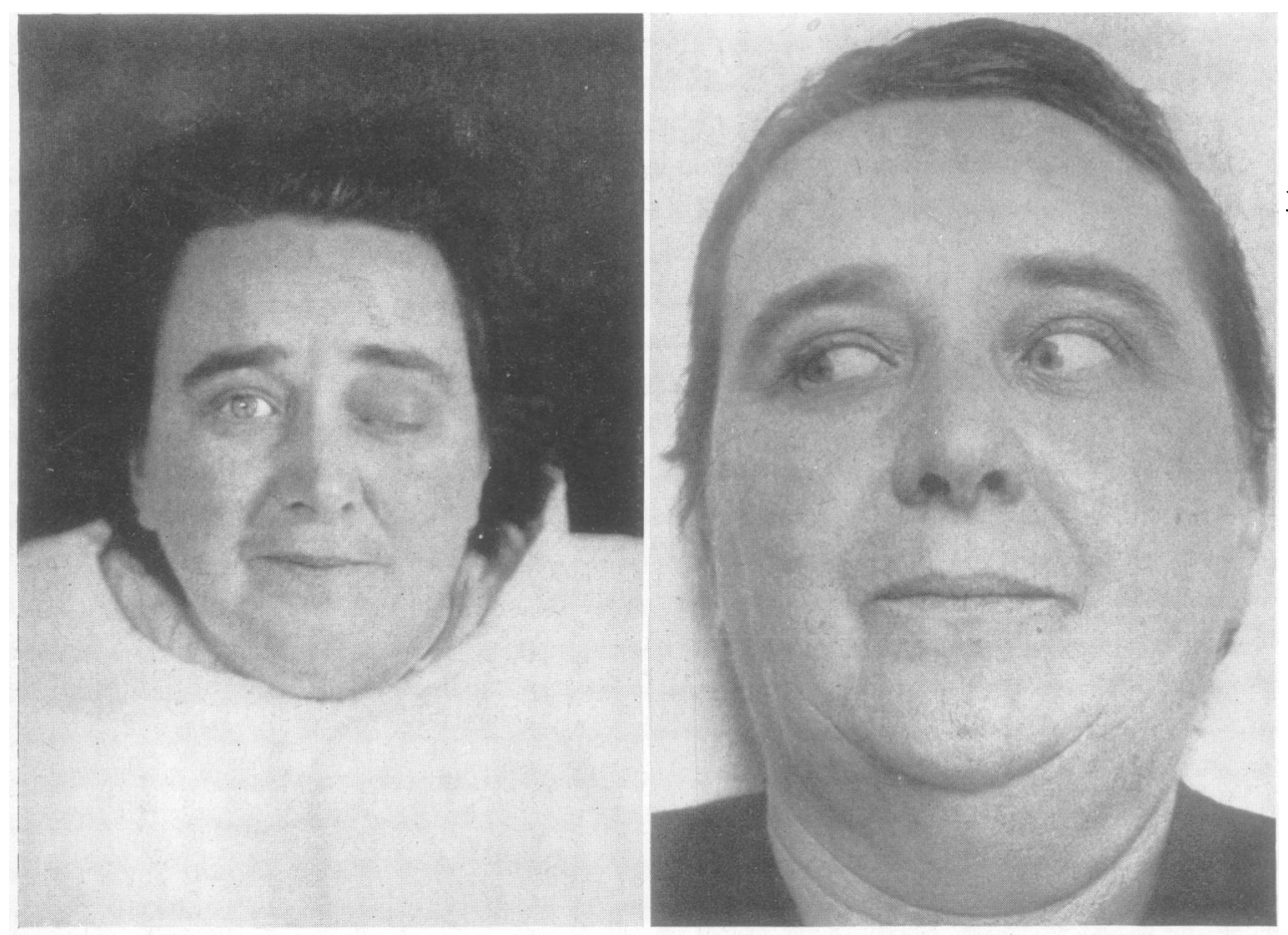

FIG. 10.-Photographs showing recovery of third nerve palsy. On the left, 14 days after carotid ligation and just before trapping, the left third nerve palsy (already improving slightly as eyelid is beginning to elevate) is seen. On the right, two and a half months later almost complete recovery is seen. (The left pupil is still slightly larger than the right; later it became of equal size.)

circle of Willis right from the time of carotid ligation. Again, in two cases of aneurysm in this particular subgroup, percutaneous arteriography of the opposite carotid artery was performed 15 or 16 months respectively after the ipsilateral internal carotid artery had been ligated. One of these cases had been complicated by a post-ligation hemiplegia, and in this case the aneurysm did not outline although both anterior and both middle cerebral arteries were filled; presumably there had been a spreading thrombosis of the internal carotid artery at the time of the hemiplegia and this had occluded the segment of the artery which bore the aneurysm. In the other case, which had not been complicated by a post-ligation hemiplegia, the new arteriograms outlined not only the anterior and middle cerebral arteries on both sides of the brain, but also a small pouch at the site of the aneurysm ; evidently there had been no comparable spreading thrombosis and the aneurysm was still filling by reflux from the circle of Willis, although part of its lumen had thrombosed. That these surmises are probably correct was suggested by a third case, one originally presenting with a third-nerve palsy but without subarachnoid haemorrhage, and then treated by internal carotid ligation. Four years later this particular patient died of a ruptured aneurysm of the basilar artery, and at necropsy the original aneurysm on the internal carotid artery, although partly thrombosed, still had a lumen which filled by reflux from the circle of Willis.
Another observation emphasizing the advantages of intracranial surgery in aneurysms of this subgroup is that the ophthalmoplegia recovered completely in two out of three cases with a complete (as opposed to a partial) third cranial nerve palsy which were treated by trapping (Fig. 10), whereas only a partial recovery was observed in each of five cases with a complete third-nerve palsy treated only by carotid ligation. If the aneurysm is excluded from the circulation it presumably will thrombose completely, whereas it may not do this if it can still fill by reflux from the circle of Willis. Consequently, after completing carotid ligation, an intracranial attack was made in 10 patients, most of them being the more recent cases. All 10 patients survived, and nine made good recoveries. In each instance the aneurysm, being on the posterior aspect of the internal carotid artery, lay deep to the artery. In nine of the 10 cases the aneurysm was trapped by placing a silver clip across the internal carotid artery above the neck of the aneurysm and yet at the same time below the circle of Willis so that blood could still flow into the middle cerebral artery from the anterior cerebral artery. In the remaining case a homonymous upper-quadrantic hemianopia had been observed pre-operatively, and at operation a large haemorrhage was found within the temporal lobe adjacent to the aneurysm, and was sucked out from the mesial aspect of the temporal lobe. The aneurysm itself proved too high for clipping without simul- 


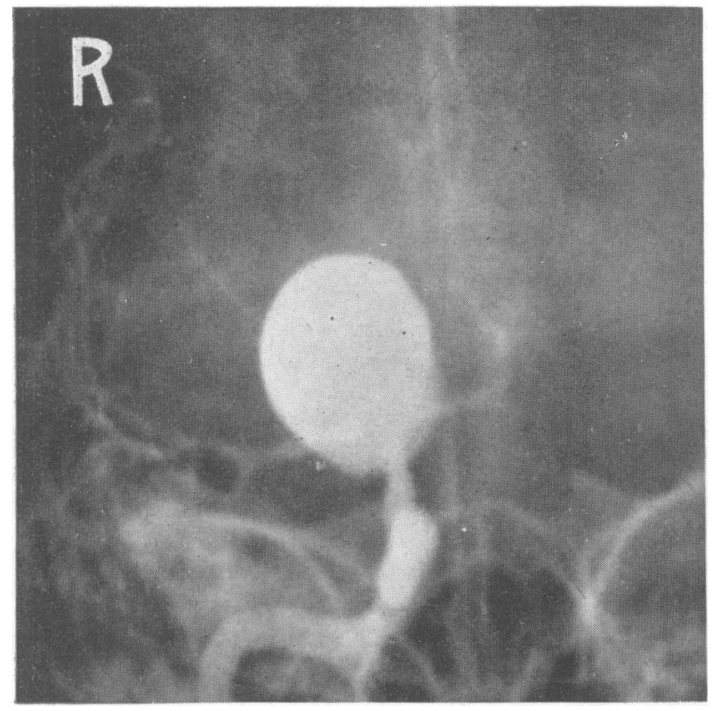

taneously occluding the origins of the anterior and middle cerebral arteries, and so it was instead packed around with muscle pledgets. The patient made a good recovery, although, of course, he still has his hemianopic defect.

In the case in which the results of trapping were disappointing the patient towards the end of the first postoperative day developed a profound hemiplegia and aphasia which has persisted ever since (one year). Presumably a thrombosis of the internal carotid artery had spread upwards into the bifurcation from the region which was clipped; how frequently such a complication could be expected in a larger series of cases I do not know. Recently Matson and Woodhall (1948) reported another possible complication, viz. blindness of the homolateral eye, which presumably is due to infarction of the retina caused by a cessation of the blood-flow to the ophthalmic artery and its central retinal branch. Fortunately the collateral circulation of the retina is almost always adequate, and this complication of blindness was not seen in my series*.

\section{Aneurysms at the Bifurcation of the Internal Carotid Artery}

Four of our 50 patients had aneurysms in this situation, one patient having two aneurysms, one on each side of the circle of Willis. All five aneurysms

* In another recent case a hemiplegia developed about 20 hours after intracranial trapping. Drowsiness, and then coma, supervened, and the patient died on the fourth day. Post-mortem examination showed necrotic changes in the territory of the middle cerebral artery, but the artery itself was not thrombosed, neither was the anterior cerebral artery nor the internal carotid artery at its bifurcation. Presumably arterial spasm had occurred in this case also.
Fig. 11.-Arteriogram demonstrating large aneurysm at bifurcation of internal carotid artery.

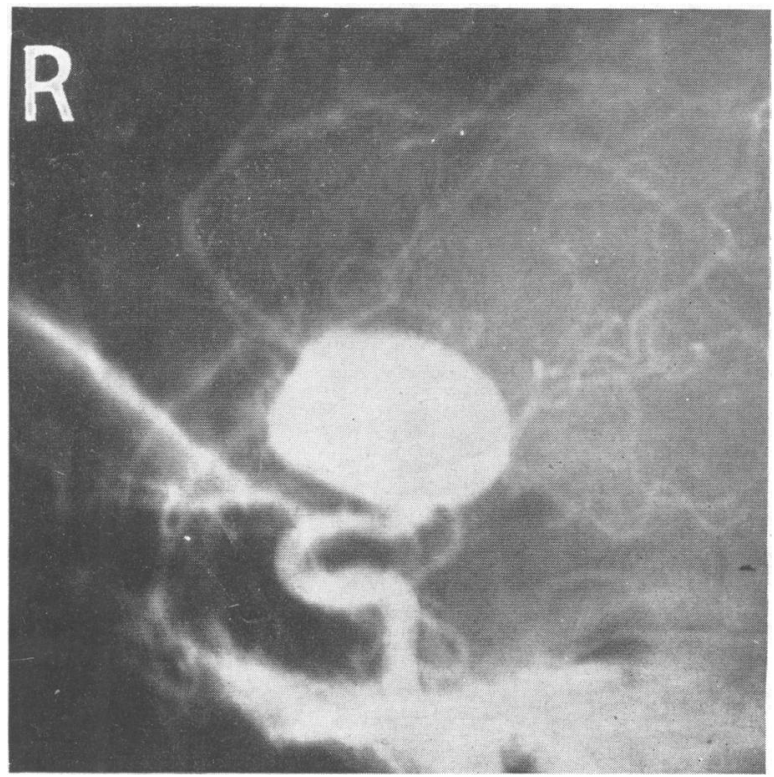

were treated by an intracranial attack which in two instances was preceded by common carotid ligation. All the patients survived, three making excellent recoveries, and one being left with a slight disability.

These results are particularly gratifying because Dandy (1944) at first regarded a direct attack on aneurysms in this situation as impracticable for fear that the origins of anterior and middle cerebral branches would be occluded. Later he had a case in which, after having first occluded the internal carotid artery with a clip, he caught one of these aneurysms in the mouth of a metal sucker and shrivelled it with the diathermy current. This method, however, is dangerous, for several of the aneurysms in various sites, which Dandy treated in this way, ruptured shortly afterwards.

Except for variations in size the arteriographic appearances were similar in each case, the aneurysm being seen in both the lateral and antero-posterior views as projecting upwards from the bifurcation (Figs. 11-13). In one case there was a slight hemiparesis and in another a subhyaloid haemor- 

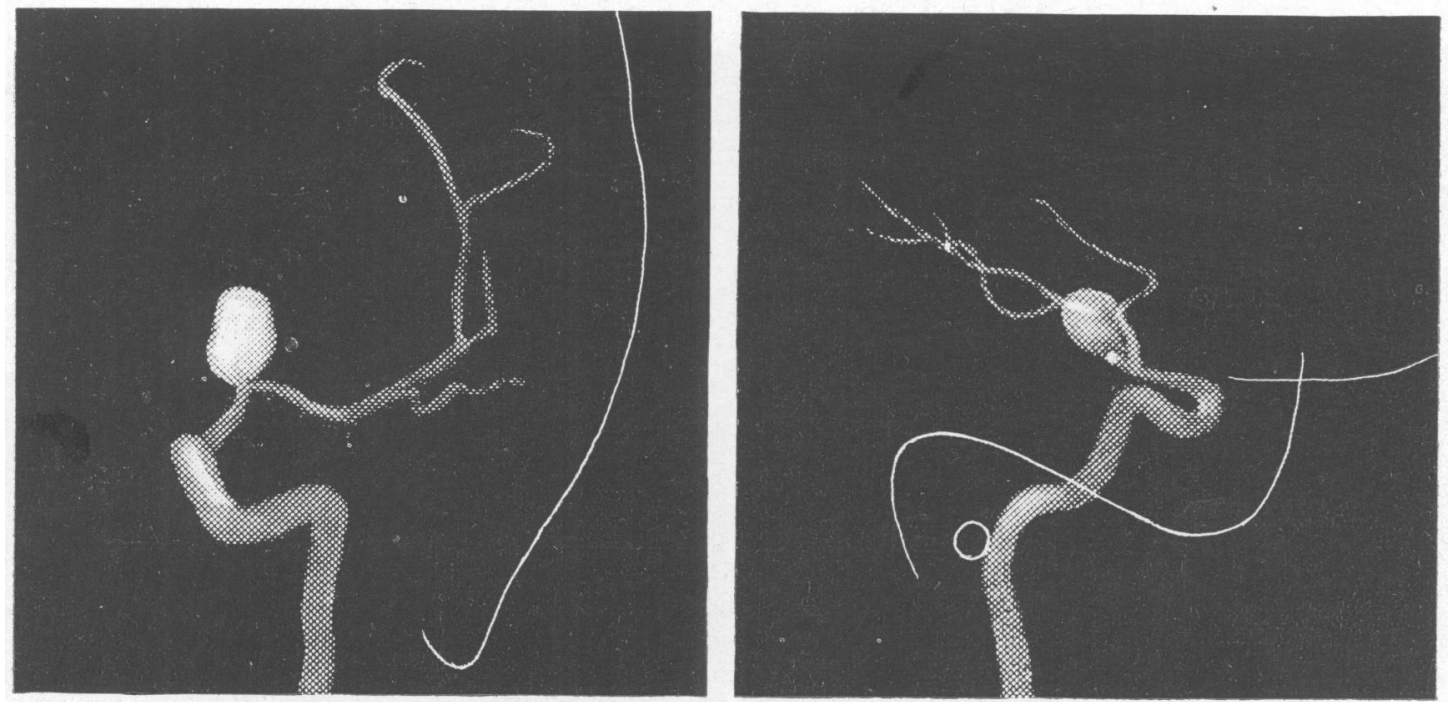

FIG. 12
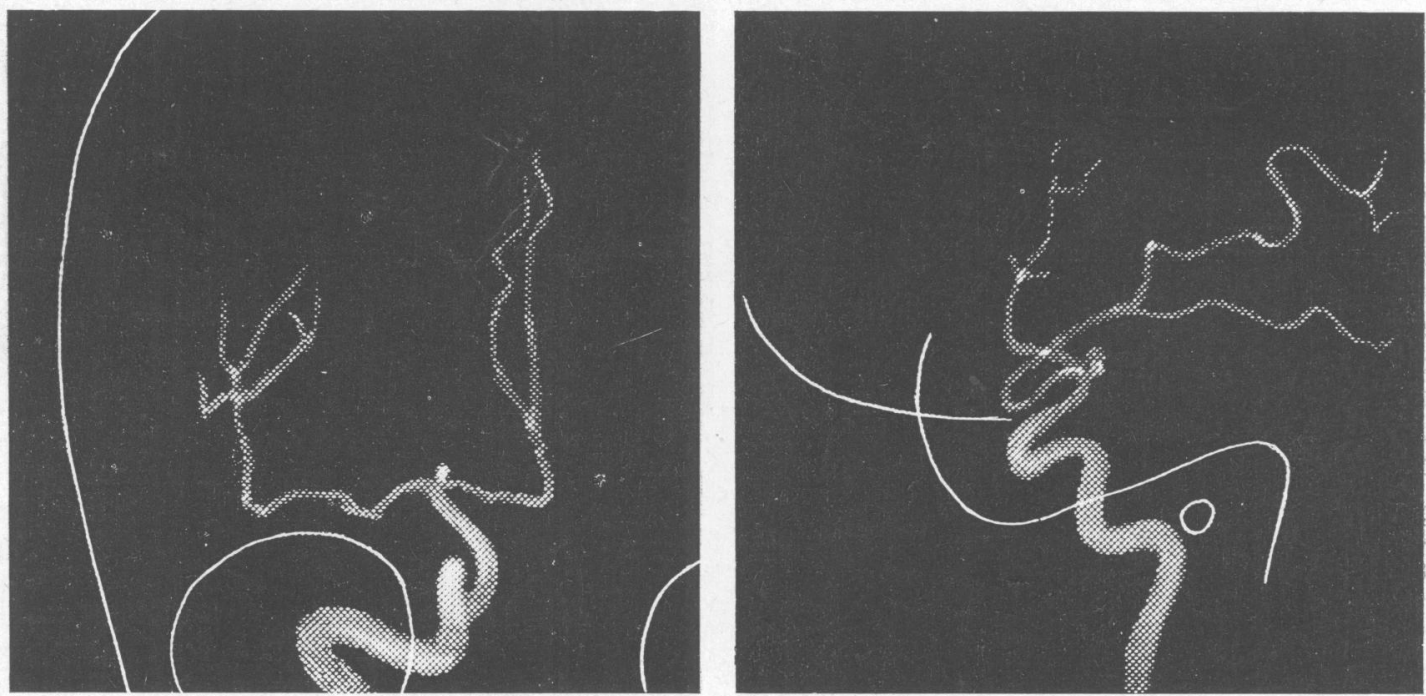

FIG.13

Figs. 12 and 13.-Tracings of arteriograms of other aneurysms at the bifurcation of the internal carotid artery.

rhage, but as a group these aneurysms are generally without localizing signs.

Carotid ligation cannot have more than a temporary effect with aneurysms in this situation, for once the collateral circulation builds up, the blood pressure within these aneurysms must reach former levels. It was utilized in one of my cases, but in this case as well as in the other three cases, the chief resort was to a direct intracranial attack. A variety of methods for dealing with the aneurysm was employed. In the first two cases, both with aneurysms less than $5 \mathrm{~mm}$. in diameter and so too small to "take" a clip, the lesion was treated by wrapping with muscle. In the third case, one with an enormous aneurysm complicated by hemiparesis, the medial and lateral sides as well as the anterior aspect of the aneurysm were wrapped with a layer of surgical gauze as well as muscle, after preliminary carotid ligation had been carried out. This patient has since continued to show a persisting hemiparesis, of moderate severity, but she is able to do all her housework. In the fourth patient, who had two aneurysms, the neck of each aneurysm was sufficiently narrow to be occluded by a clip. The case 
history of this particular patient has been reported elsewhere (Falconer, 1950).

From my experience of this subgroup I feel that aneurysms situated at the bifurcation of the internal carotid artery may be treated in the first instarice by carotid ligation, but that wherever possible this should be followed by an intracranial approach.

\section{Aneurysms of the Middle Cerebral Artery}

There were 10 cases in my series, seven of which made good recoveries, one recovered with an appreciable disability, and two died. Three cases exhibited massive haemorrhages within the temporal lobe, and only one of these recovered. One of the fatal cases had two aneurysms, one on each middle cerebral artery. My impression is that aneurysms in this subgroup should be treated whenever possible by an intracranial attack with wrapping of muscle around the aneurysm, as probably the best local measure. Any associated intracerebral clot should be removed.

Few reports of operations on aneurysms of the middle cerebral artery appear in the literature. Dandy (1944) reported having operated on four cases, but without any successful result. Since then Swain (1948) records having operated on three cases with success in two. Swain approached each aneurysm either across the Sylvian fissure or by an incision through the temporal lobe. $\mathrm{He}$ then caught the fundus of the aneurysm in the mouth of a metal sucker, and simultaneously coagulated it with a diathermy current. This method, however, when used by Dandy for aneurysms in other situations, often proved hazardous, as in several cases delayed rupture of the aneurysm occurred. Recently Sweet, Sarnoff, and Bakay (1950) have recorded a case in which internal carotid ligation was performed for an aneurysm of the middle cerebral artery. Eighteen months later their patient had another attack of subarachnoid haemorrhage, this time with hemiparesis of the opposite side. They therefore presumed that the aneurysm of the middle cerebral artery was again causing symptoms, and that it was being supplied from the carotid artery of the opposite side as well as from the basilar system. Consequently they exposed the opposite common carotid artery under local analgesia, and clamped it for a period of 30 minutes. As anoxic symptoms had not appeared during the period of clamping, they then ligated the exposed common carotid artery. Thus this case of middle cerebral aneurysm in effect was treated by bilateral carotid ligation, a testimony to the way in which the basilar artery will sometimes take over the functions of both cerebral arteries. No attempt apparently was made at a direct intracranial exposure.
The arteriographic appearances in this subgroup of aneurysms are likewise characteristic, and require a good antero-posterior view as well as a lateral view for their proper interpretation (Figs. 1417). In the lateral views the aneurysm shows up clearly, but may appear superimposed upon the bifurcation of the internal carotid artery. With this projection alone it may be impossible to distinguish these from aneurysms arising at the bifurcation or sometimes even on the anterior communicating artery. In antero-posterior views, however, the aneurysm is depicted on the middle cerebral artery, usually at its first point of branching about $2 \mathrm{~cm}$. distal to the bifurcation. But, as in this projection the aneurysm is at a much greater distance from the film than in the lateral view, its edges are usually indistinct and its size seems greater than in the lateral view.

Experiences with Carotid Ligation.-Seven of my cases were treated in the first instance by carotid ligation on the same side of the neck (primary stage-ligation of the common carotid artery, six cases ; primary internal carotid ligation, one case). In four cases this was the only surgical treatment, largely because in three of these four cases the carotid ligation was followed by hemiplegia. In one of these three cases, a woman of 66 years, the hemiplegia appeared suddenly six days after stageligation of the common carotid artery had been completed, and fortunately within a few days it began to improve so that after a short period there was little trace of it. In the second case, a woman of 55 years, the common carotid artery was tied in two places and divided between them, a method of ligation recommended by Rogers (1947) as minimizing the risk of hemiplegia; yet a hemiplegia appeared within 24 hours and persisted for five months before finally disappearing. In the third patient, a man of 28 years, the left common carotid artery was successfully ligated in two stages followed by left internal carotid ligation in a further stage. Three days after the ligation had been completed the patient awoke from sleep unable to raise his right arm and unable to speak properly. Heparin therapy was started forthwith for a period of 24 hours, but observations were made which in retrospect suggest that spasm of cerebral arteries was. responsible for this complication rather than embolism or thrombosis. First, the laboratory reports when they came to hand showed that the blood coagulation time was within normal limits, but that the prothrombin concentration in the blood had been only $40 \%$ of normal when heparin therapy was begun. This seemed an argument against a clotting diathesis. Secondly, a procaine. 


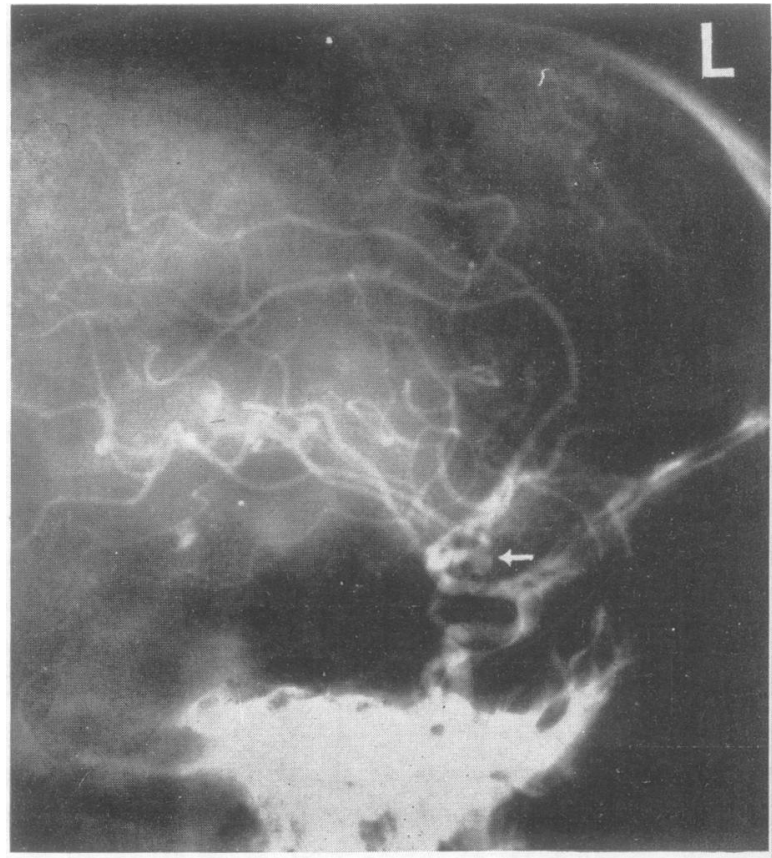

FIG. 14.-Arteriogram demonstrating aneurysm (arrow) of middle cerebral artery.
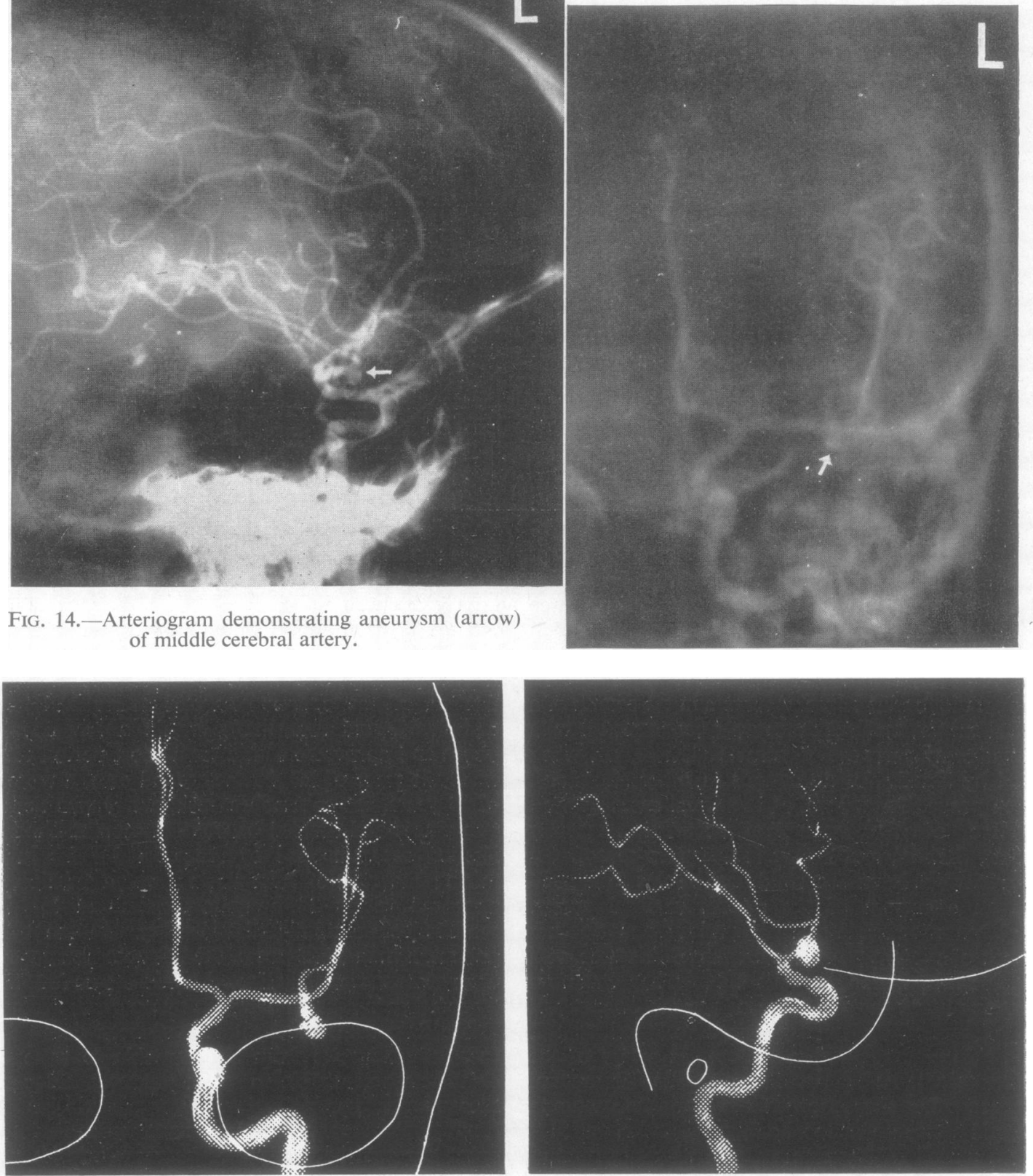

FIG. 15

block of the stellate ganglion produced prompt improvement which lasted for about three hours. This was followed by repeated injections of tetraethyl ammonium-bromide solution $(2 \mathrm{ml}$. intramuscularly every two hours), each injection being associated with steady improvement. Thirdly, in this particular patient, when a percutaneous arterio-

gram was performed on the opposite carotid artery several weeks afterwards, the left middle cerebral artery and the aneurysm appeared to fill normally.

From these cases, and also from another case, in which a partial common carotid occlusion was attempted but was not tolerated because of anoxic symptoms, it would seem that common carotid 

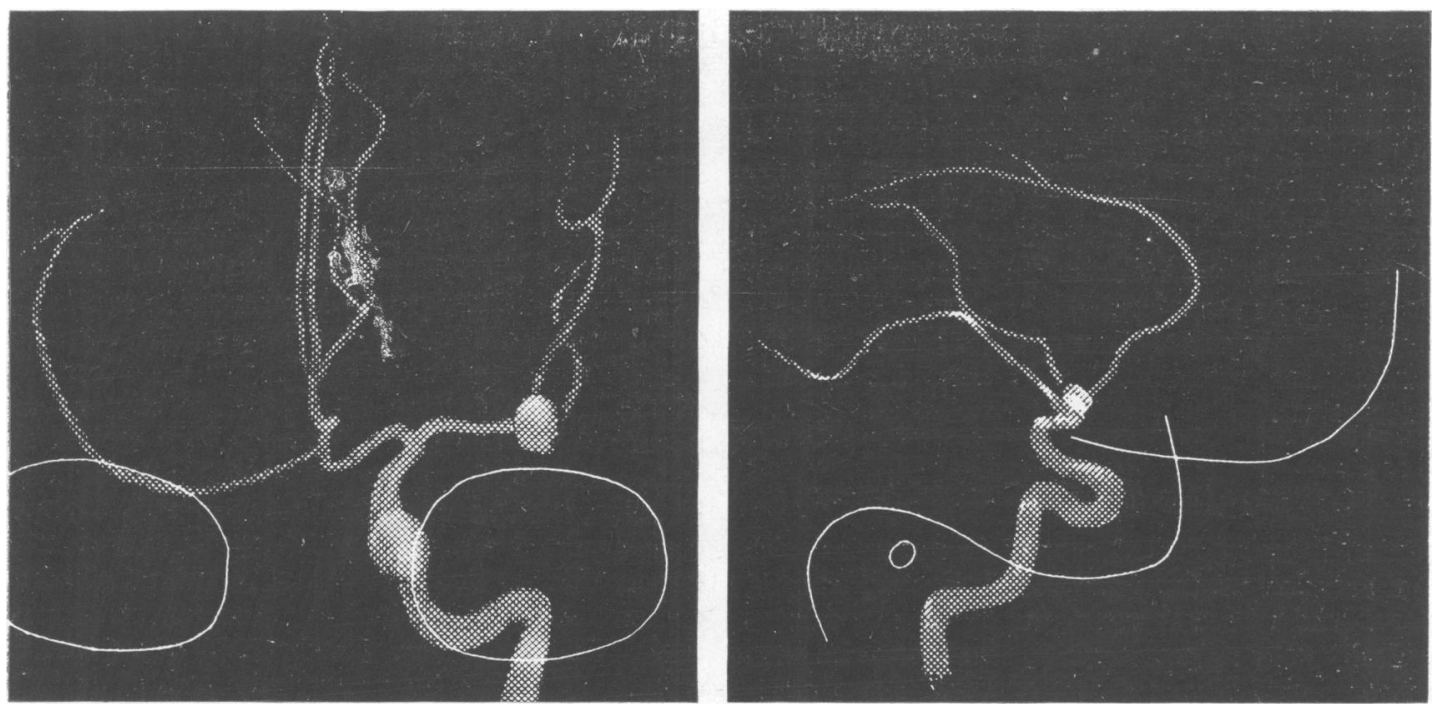

FIG. 16
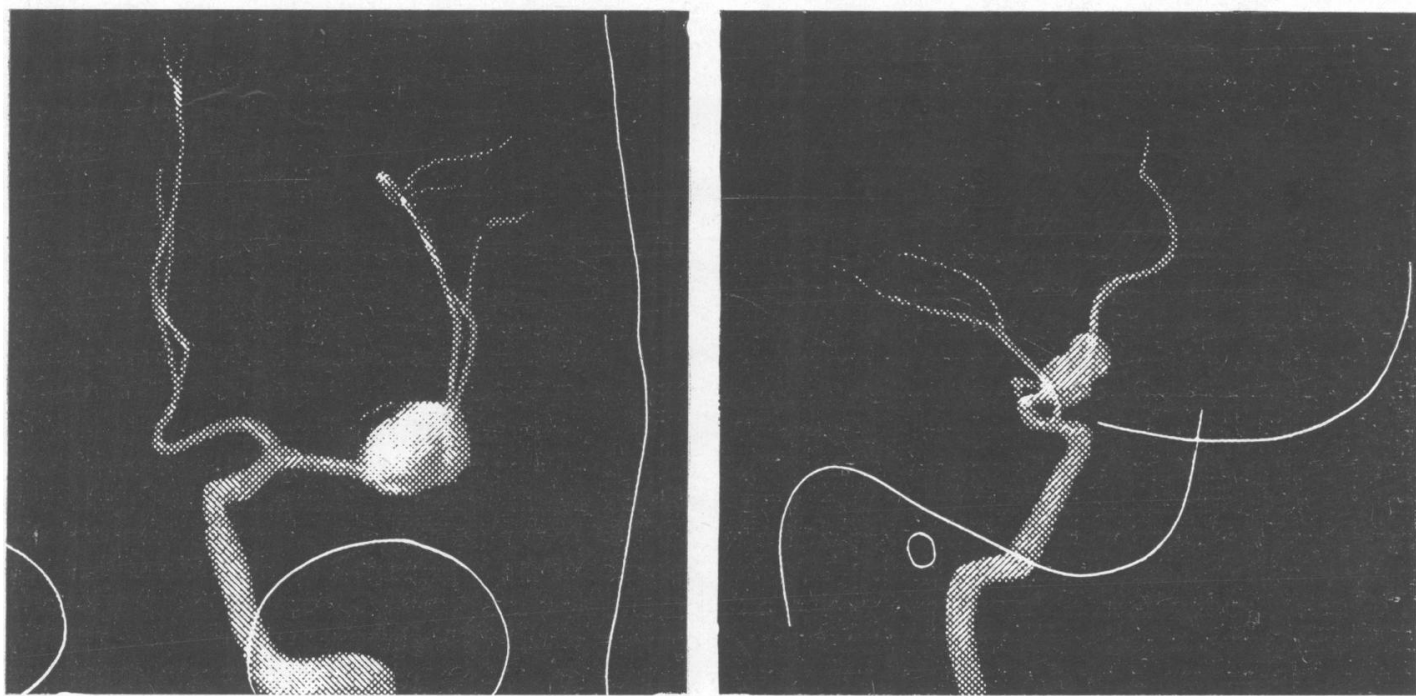

FIG. 17

Figs. 15, 16, and 17.-Tracings of arteriograms of other aneurysms of middle cerebral artery.

ligation carries increased hazards in the presence of an aneurysm of the middle cerebral vessels, and that arterial spasm plays a part in producing symptoms.

Experiences with Intracranial Operation.-Six cases were submitted to an intracranial operation, which in three instances was preceded by common carotid ligation. In each instance the fissure of Sylvius was opened up as described earlier, and the aneurysm was well seen. Three of the patients made excellent recoveries; one recovered with a hemiplegia ; and two died.
The three cases which made good recoveries were treated in two instances by wrapping the aneurysm with muscle, and in one by clipping the neck of the aneurysm. In one of these cases the aneurysm was associated with a large temporal lobe haemorrhage which was successfully sucked out. In the case that recovered with a hemiplegia, an attempt was made at operation to clip the neck of the aneurysm, but the clip tore the sac causing brisk bleeding which was then controlled by wrapping with muscle. The two cases which ended fatally were both found at operation to have large clots within the temporal lobe, and these clots were 
evacuated. At the subsequent necropsy each temporal lobe was found to be extensively lacerated. In one of the two fatal cases a second and smaller aneurysm was found on the opposite middle cerebral artery, as had been previously suggested by the arteriograms.

An interesting but unexplained observation is that in eight of my 10 cases the leaking aneurysm was located on the left middle cerebral artery in the dominant hemisphere. Four of these cases exhibited aphasia after operation, but in three the aphasia was transient.

\section{Aneurysms of the Anterior Cerebral Artery}

This subgroup ranked second in numerical size to aneurysms of the intracranial internal carotid artery. There were 17 cases, and these were treated surgically with 10 good results, two recoveries with persisting disability, and five deaths. These aneurysms are a more difficult proposition to treat than are the aneurysms of the internal carotid artery. Often they are readily supplied with blood from both internal carotid arteries, and so carotid ligation may not be effective. Again, leaking aneurysms in this situation, like aneurysms of the middle cerebral artery, are likely to cause massive intracerebral haemorrhage (into the frontal lobes) as well as subarachnoid haemorrhage (Richardson and Hyland, 1941). For these reasons a direct intracranial attack is frequently necessary in order to save life.

Dandy (1944) evidently encountered at operation six cases in this situation, and had success in two of these. Only two of his cases gave a history of recent bleeding, and both of these died. However, there are six reports in the literature where an aneurysm of the anterior cerebral artery, that had recently bled, was successfully attacked. Tönnis (1936) after having located by arteriography an aneurysm on the anterior communicating artery, attempted to expose it by a subfrontal approach, but was unsuccessful. He then retracted the mesial surface of the frontal lobe from off the falx, and split the anterior part of the corpus callosum. In this way he came down upon the aneurysm from above, and covered it with muscle. Cone (quoted by Russel, 1939), operating on a case, in which air-encephalography had disclosed a space-occupying lesion in the inferior frontal region, evacuated a clot from the frontal lobe, and found a small aneurysm on the anterior communicating artery projecting into the operation cavity. This he was able to excise. List and Hodges (1946), having demonstrated by arteriography an aneurysm on the left anterior cerebral artery close to the bifurcation, exposed the subfrontal portion of the anterior cerebral artery, and placed silver clips on this artery on either side of the aneurysm with an excellent result. Sugar and Tinsley (1948) described a case of aneurysm of the distal part of the anterior cerebral artery in which, some time after an attack of subarachnoid haemorrhage, they clipped the artery a little proximal to the aneurysm. Recently Elvidge and Feindel (1950) reported that they had successfully dealt with two cases of aneurysm in relation to the anterior communicating artery. In one they clipped the anterior cerebral artery on either side of the communicating artery, before clipping the aneurysm itself. In the other case they excised the sac. Besides these six cases with subarachnoid bleeding, McConnell (1937) and Dandy (1944) have each reported a case in which they encountered a large, thick-walled aneurysm causing chiasmal compression, and had incised the aneurysm, packing muscle into its interior. Dandy (1944) also described a case in which he successfully excised a large aneurysm in this region, presumably at the same time sacrificing a segment of one anterior cerebral artery.

As the surgical problems differ according to which part of the anterior cerebral artery is involved, my 17 cases will be considered in three sections, as follows :-

(1) aneurysmus of the proximal portion of the

(2) aneurysms involving the anterior communicating artery $\quad \ldots \quad \ldots \quad \ldots \quad \ldots 11$

(3) aneurysms of the distal portion of the artery 4

(1) Aneurysms of the Proximal Portion of the Artery.-There were two cases, both of which were treated by an intracranial attack. Both survived, but the result in the first case was disappointing because of an unexpected complication. In both cases the aneurysm was situated on the anterior cerebral artery a little proximal to the communicating artery, and the arteriographic appearances are illustrated in Figs. 18 and 19. Possibly these two cases may have been examples of the more common subgroup of aneurysms in relation to the communicating artery, although at operation they appeared away from that artery.

In the first case (Fig. 18) a small aneurysm was exposed on the left anterior cerebral artery immediately above the left optic nerve, and was treated by clipping the anterior cerebral artery close to the bifurcation. I had anticipated that this procedure would carry very little risk, because List and Hodges (1946) had successfully trapped an aneurysm in this same situation, and because the arteriograms had shown that, distal to the communicating artery, both anterior cerebral arteries were receiving their 

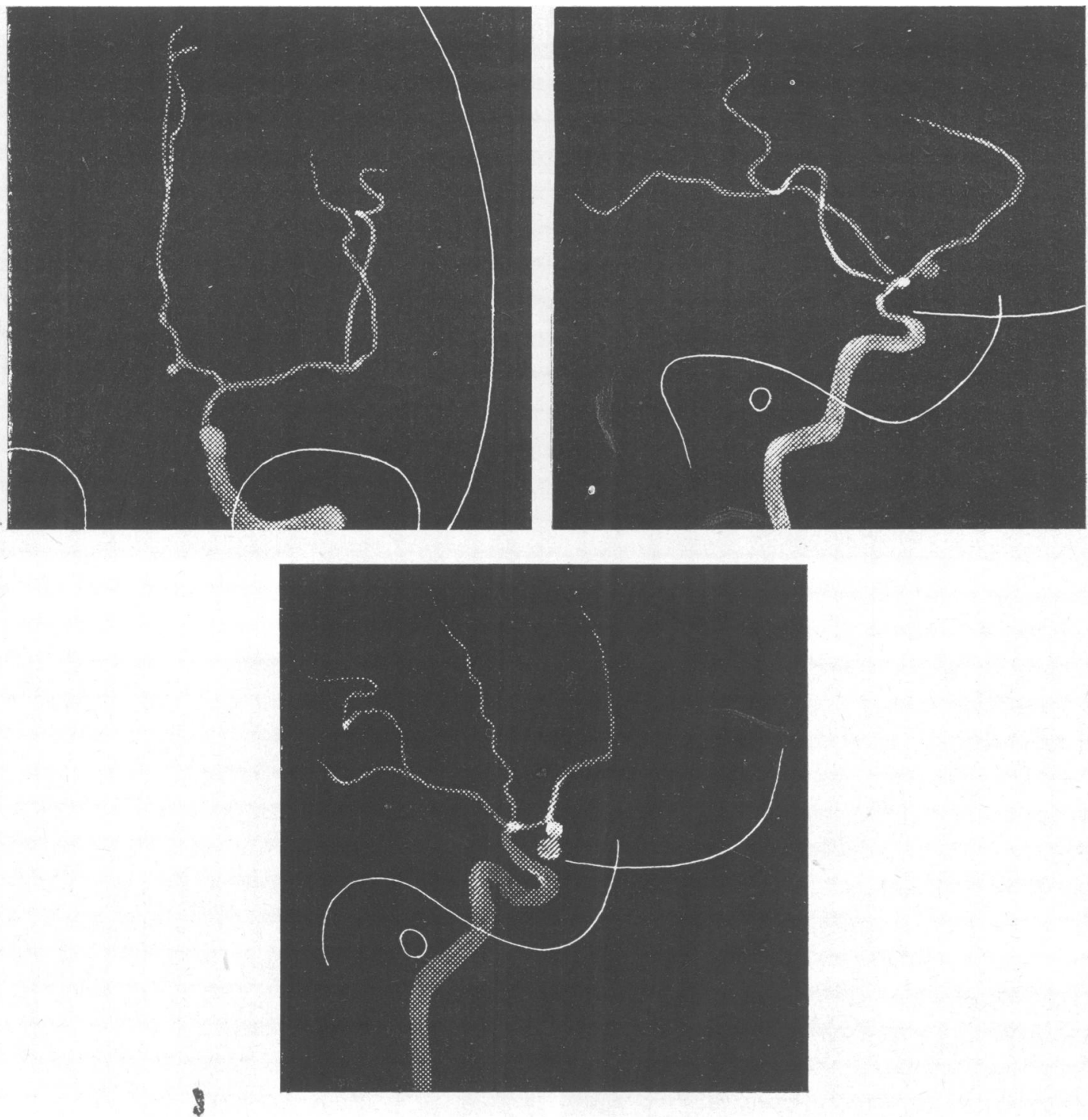

Figs. 18 and 19.-Tracings of arteriograms of aneurysms of the proximal portion of the anterior cerebral artery.

major supply from the internal carotid of the opposite side. However, on the second postoperative day the patient unexpectedly developed pronounced aphasia and a right-sided hemiparesis which affected principally his arm, and not his leg, as might probably be expected with a thrombosis of an anterior cerebral artery. Postoperative arteriograms, however, confirmed that the clip had been placed on the left anterior cerebral artery, and that only the segment of the artery proximal to the com- municating artery was thrombosed. The patient has now been followed for three years, and still exhibits a residual aphasia and hemiparesis.

The explanation presumably lies in the existence of Heubner's artery (medial striate artery) described in such a masterly fashion by Critchley (1930). One of the basal perforating branches of the circle of Willis, this artery normally arises from the anterior cerebral artery, but sometimes instead from the middle cerebral artery or even from the internal 


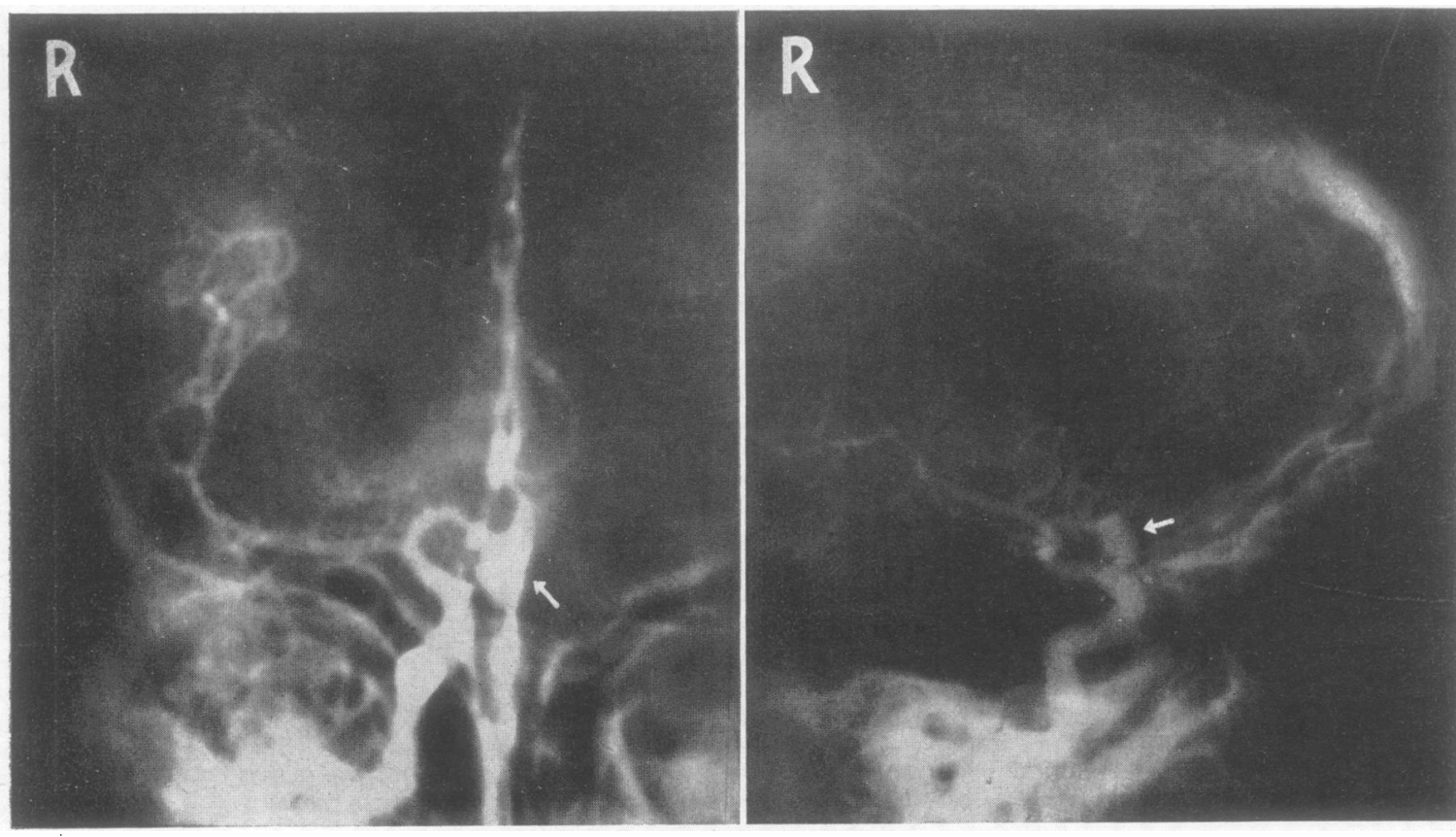

Fig. 20.-Arteriogram demonstrating aneurysm (arrow) projecting downwards and forwards from the anterior communicating artery.
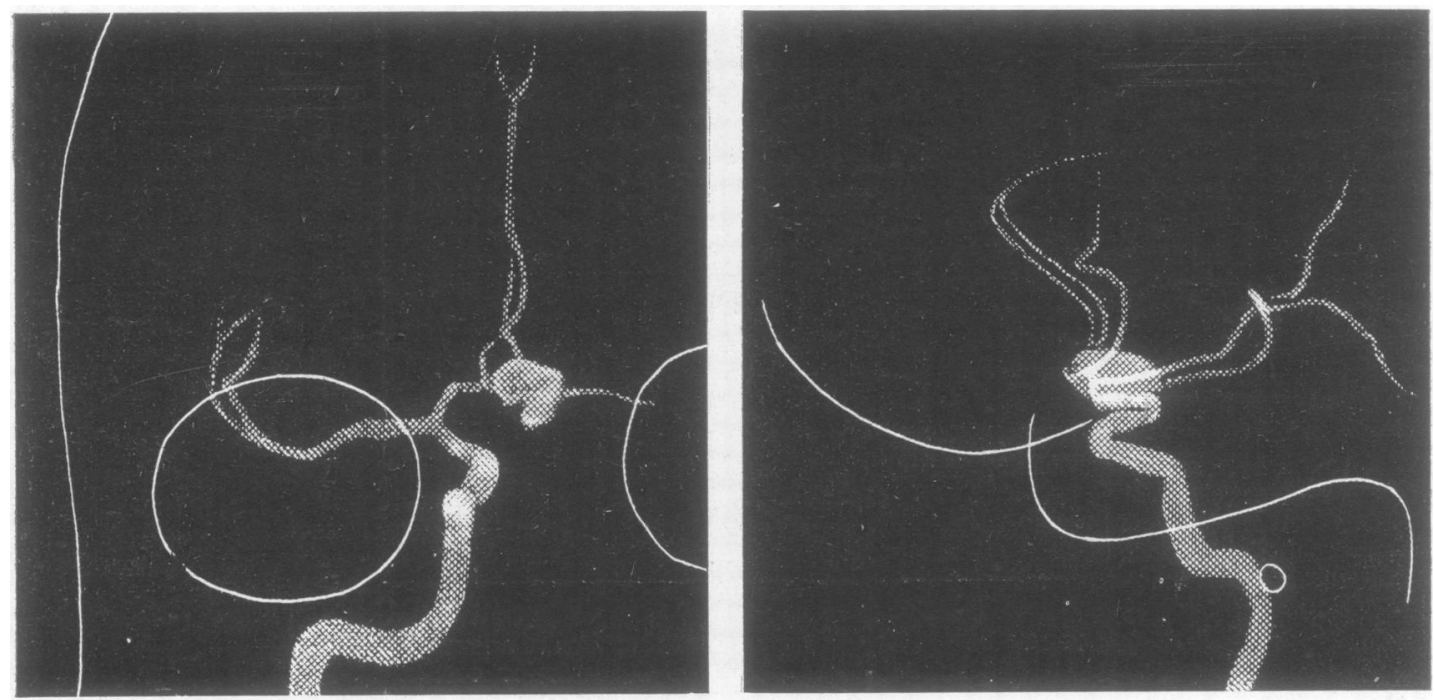

FIG. 21

carotid artery. It enters the anterior perforated

Heubner's artery at operation, it may have arisen from the anterior cerebral artery distal to the point of clipping and affected by the thrombosis of this vessel.

After this experience the next aneurysm encountered in this same situation (Fig. 19), was, after exposure, merely wrapped round with pledgets of hammered muscle. The patient made a gratifying recovery. My experience with these proximal anterior cerebral aneurysms, however, is still too 

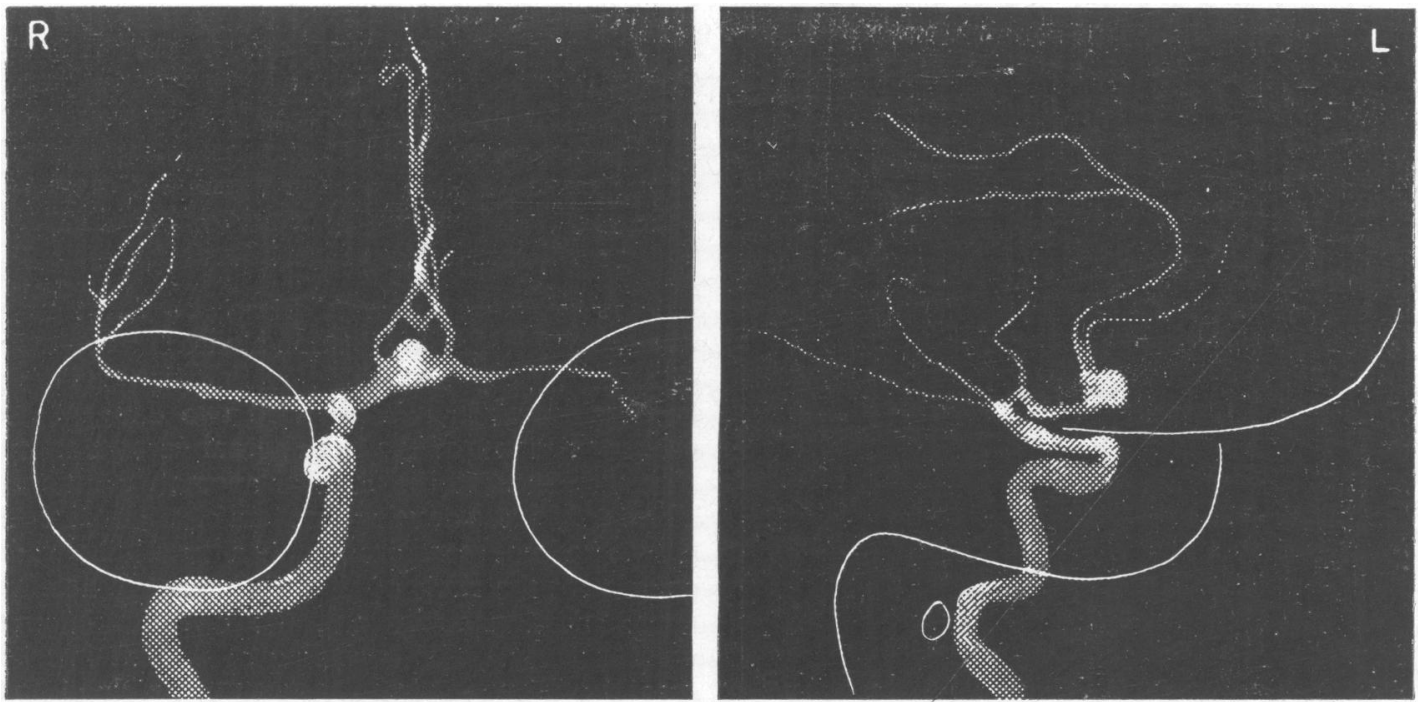

FIG. 22
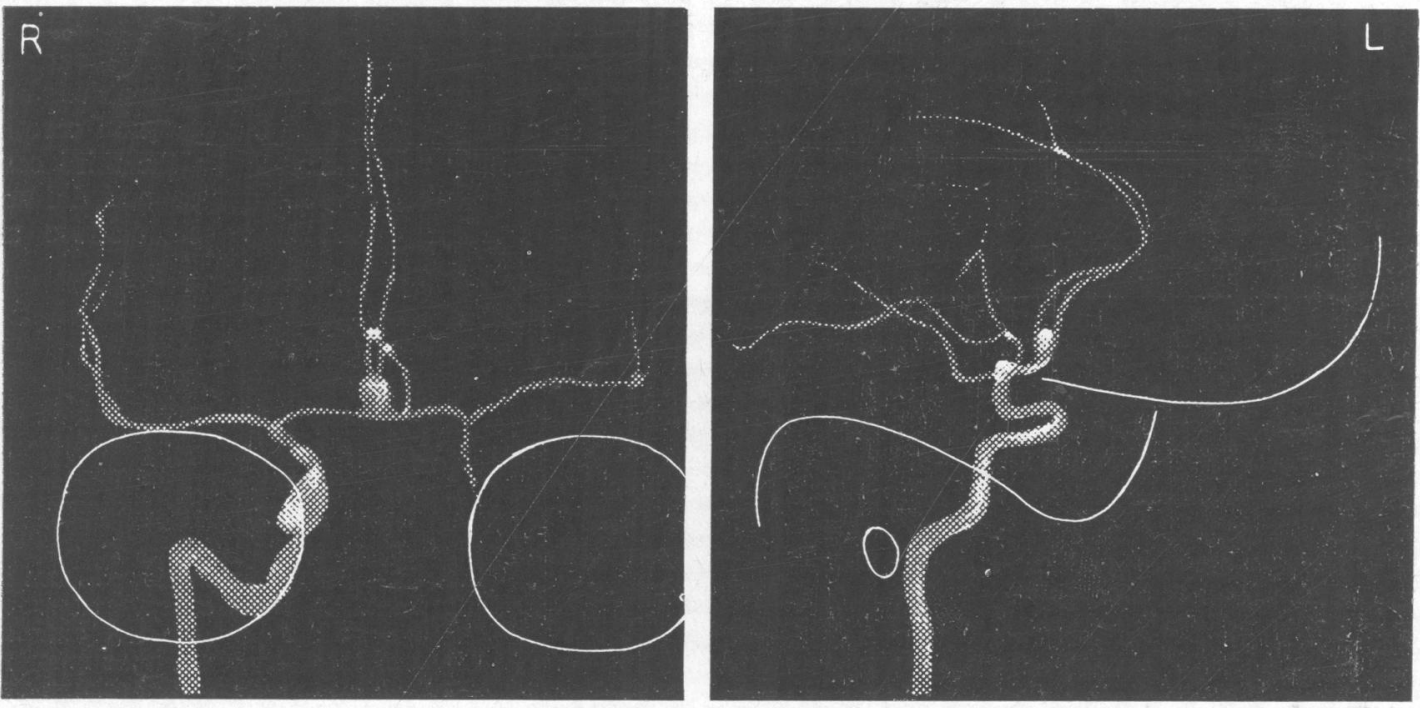

FIG.23

Figs. 21, 22, and 23.-Tracings of arteriograms of other aneurysms of the anterior communicating artery.

scanty to permit of generalizations about the best method of treatment.

(2) Aneurysms Involving the Anterior Communicating Artery.-There were 11 cases, seven of which made good recoveries, one recovered with a peculiar mental disability, and three died. Three cases were associated with intracerebral haemorrhage, in two instances into the frontal lobe, and in one into the corpus callosum. The conclusion reached was that, whenever practicable, these aneurysms are best treated by an intracranial approach, exposing the aneurysm and wrapping it around with hammered muscle.

The arteriographic appearances of these aneurysms have a common pattern (Figs. 20 to 23). In antero-posterior views the aneurysms are situated in the midline, or almost so, between the two anterior cerebral arteries, while in lateral views the aneurysmal sac projects either downwards and forwards, or upwards and backwards. In five out of our 11 cases there was an anomaly of the circle of 


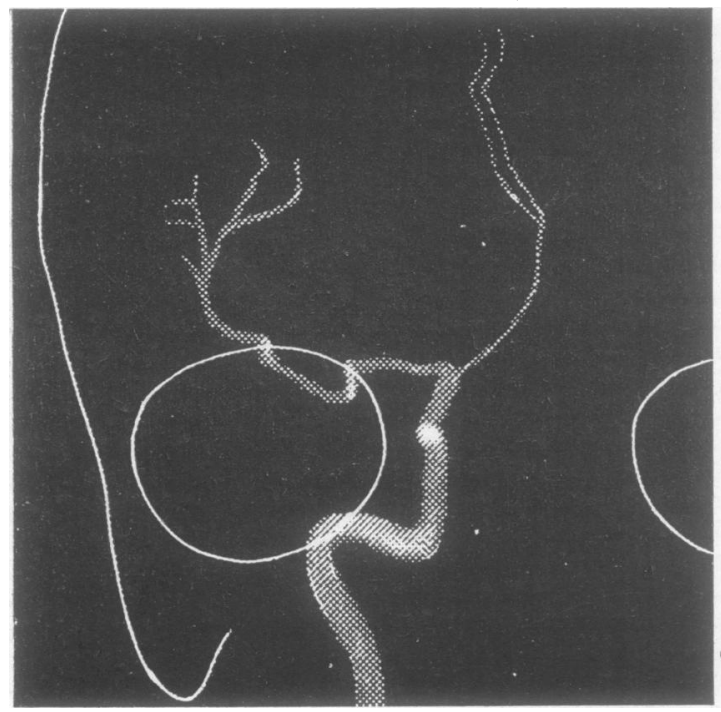

FIG. 24.-Tracing of arteriogram showing shift of the right anterior cerebral artery to the left side, indicating a space-occupying lesion within the frontal lobe.
Willis, such that, distal to the communicating artery, both anterior cerebral arteries were supplied from one carotid artery only, suggesting a deficiency in the circle of Willis between the anterior communicating artery and the internal carotid artery of the opposite side. In the remaining cases the aneurysm was shown up by arteriography of carotid artery on either side (see Figs. 22 and 23).

Experiences with Carotid Ligation.-Three cases were treated by carotid ligation alone, and two died. The first of these, an obese woman, who was deeply unconscious when referred, died two days after a primary ligation of the left internal carotid artery. Necropsy revealed the vascular anomaly mentioned above (which the arteriograms had clearly indicated, but we had not recognized), only a thread-like vessel completing the circle of Willis between the anterior communicating artery and the opposite internal carotid artery. The occluding of the left internal carotid artery had virtually shut off the blood flow to both anterior cerebral arteries and so produced infarcts in both frontal lobes. In the second case, the presence of this vascular anomaly was recognized from the arteriograms, and treatment was therefore limited to a stage-ligation of the common carotid artery, apparently with success. In the third case the arteriograms were of poor quality and did not show any aneurysm, but they did disclose an

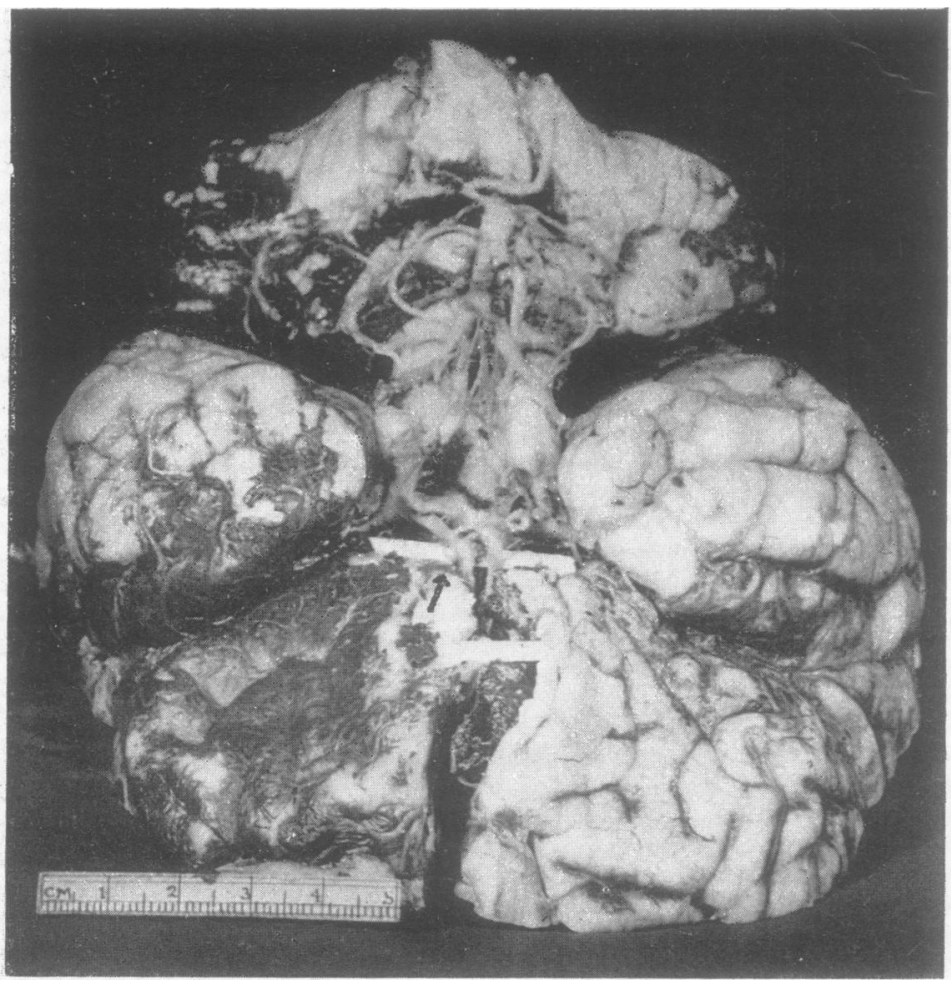

FIG. 25.-Base of brain viewed from in front. A small aneurysm (arrow) can be seen on the left anterior cerebral artery where it is supported by a white rod. Notice a large clot occupying the mesial surface of the right frontal lobe. 
appreciable shift of both anterior cerebral arteries to the left side, indicating a large haemorrhage within the right frontal lobe (Fig. 24). We therefore presumed that there was a bleeding aneurysm in the right anterior cerebral artery, and so went ahead and tied the right common carotid artery in the neck. Six hours later the patient suddenly became unconscious and died within a few minutes. At necropsy a small aneurysm was found on the opposite or left anterior cerebral artery, in the angle between that artery and the anterior communicating artery, and this aneurysm had ruptured across the midline to produce a large haemorrhage within the right frontal lobe (Fig. 25). I have since seen in museum specimens other examples of an aneurysm situated on one anterior cerebral artery rupturing into the frontal lobe of the opposite side. Sucl cases show that, in deciding the side of a bleeding lesion, reliance cannot always be placed upon the direction of the shift of the arterial tree as shown by an arteriogram of one side only, but that both carotid arteries may have to be injected before an aneurysmal sac is revealed.

These three cases taken by themselves cannot be regarded as a fair test of either common or internal carotid ligation for this subgroup of aneurysms, but they do indicate that these procedures cannot be applied in all such cases without proper safeguards. Occlusion of either carotid artery, moreover, can only have a temporary effect in lowering the intra-arterial pressure within the communicating artery pending the development of the collateral circulation. This is especially true when the preoperative arteriograms show that the aneurysm can be filled from either carotid artery. Therefore, we have come to regard a direct attack on these aneurysms, with or without preliminary carotid ligation, as the measure most likely to give permanent relief.

Experiences with an Intracranial Attack.-A direct attack was undertaken in the remaining eight cases in this section with six good recoveries, one recovery with mental impairment, and one death from recurrent bleeding. In four instances the intracranial attack was preceded by stage-ligation of the common carotid artery, but this measure was not considered worthwhile when the aneurysm could be shown up by carotid arteriograms. The six successful cases were each treated by wrapping hammered muscle around the aneurysm. One of the aneurysms was associated with a haemorrhage, the size of a walnut, in the genu of the corpus callosum, and this haemorrhage was also evacuated. We learnt that most aneurysms in this region appear to project forwards and downwards from the anterior com- municating artery, but that a few project upwards and backwards. The distinction can be readily determined from the arteriograms, and is of practical importance because, whereas the first type can often be readily exposed by a subfrontal approach alone, the second type requires the combined subfrontal and vertical approaches.

The case that died was the only one in my experience so far to suffer recurrent bleeding after a surgical attack. Two craniotomies proved necessary. At the first the aneurysm was exposed by a combined vertical and subfrontal approach, and unfortunately burst in the later stages of the manipulations to uncover it. The bleeding, however, was controlled by wrapping with hammered muscle, and the patient at first appeared to be progressing well. Three weeks later she was sent home and a few days after that she had a sudden recurrence of subarachnoid haemorrhage, necessitating her readmission. The craniotomy was reopened and a small haemorrhage within the right frontal lobe was sucked out, but the region of the anterior communicating artery was so covered with organizing muscle tissue that I was unable to define the vessels or see the bleeding point. As an alternative I then clipped the right anterior cerebral artery proximal to the communicating artery, hoping that this would lessen the blood flow through the aneurysm. For the next seven weeks the patient lay in a mute, disinterested, and motionless state before succumbing from bronchopneumonia. At necropsy the aneurysm was found still embedded in muscle. There was extensive destruction of the right frontal lobe, and there was also an area of cortical destruction about $4 \mathrm{~cm} . \times 2 \mathrm{~cm}$. on the mesial aspect of the left frontal lobe. Evidently the muscle patch used to seal the aneurysm at its first operation must have given way at the time of recurrence. In several subsequent cases we tried wrapping the aneurysm with a single layer of surgical gauze as a filigree, in addition to wrapping it with muscle.

The case of the patient, who following operation exhibited considerable mental impairment, was also instructive because it would appear that both anterior cerebral arteries were occluded. In this patient, a farm worker of 28 years, referred to us after his seventh bout of subarachnoid haemorrhage, bilateral percutaneous carotid arteriography disclosed a moderate-sized aneurysm, which we interpreted as projecting downwards and forwards from the right anterior cerebral artery, just proximal to the communicating artery (Fig. 26). Distal to the communicating artery both anterior cerebral arteries could be readily filled from either carotid artery indicating a free collateral circulation through the communicating artery. A right frontal craniotomy 

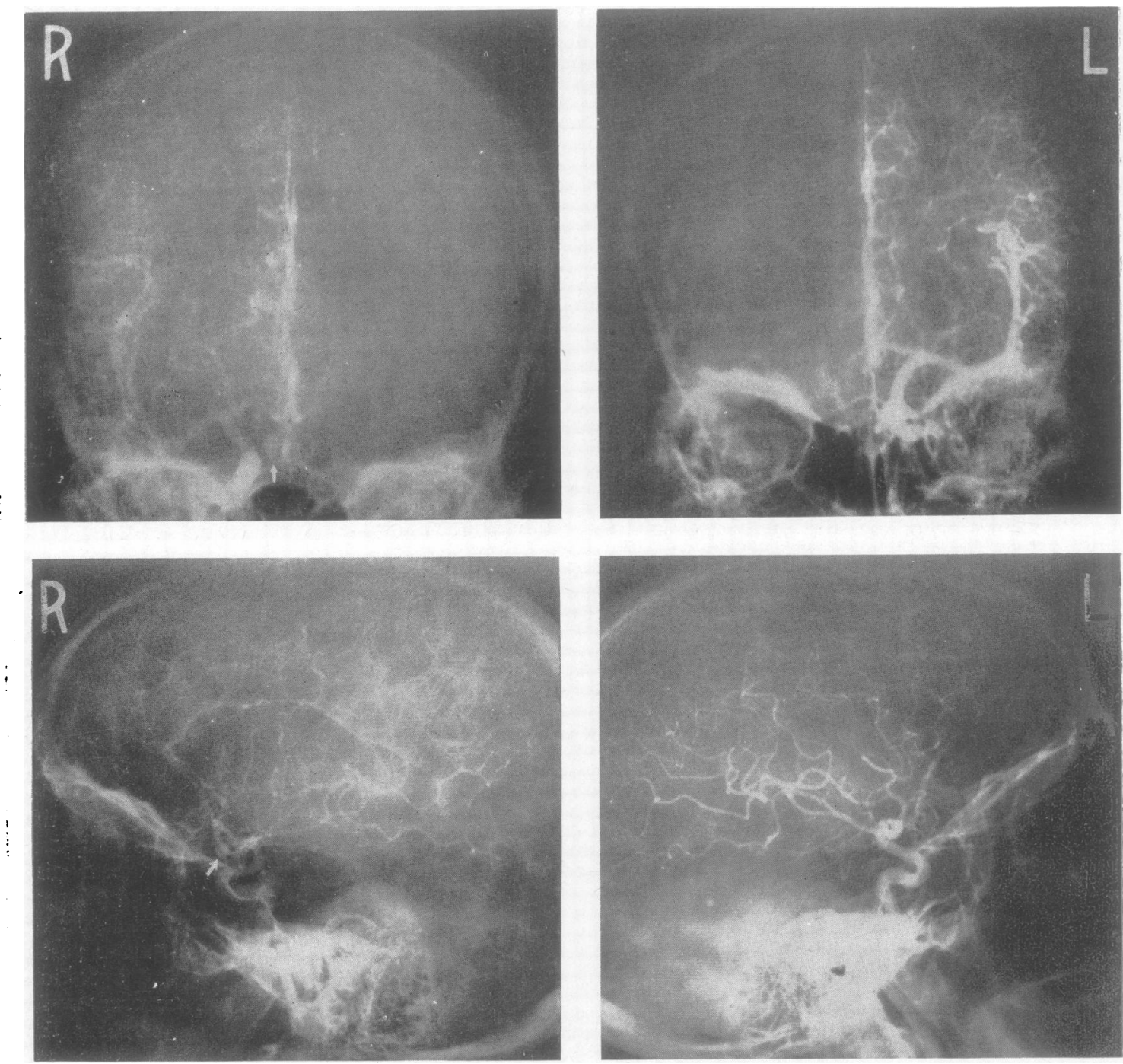

Fig. 26.-Right carotid arteriograms show aneurysm (arrow) which was interpreted as arising from the right anterior cerebral artery, but which probably arose from the anterior communicating artery. Left carotid arteriograms, shown for comparison, are normal.

was performed, and the first part of the anterior cerebral artery was exposed. An aneurysm was clearly displayed projecting downwards and forwards close to the midline. Its neck was then clipped, but unfortunately it tore and bled, and so the artery itself was hastily occluded with a second clip placed across it at the point where the aneurysm was attached, and the aneurysmal sac was coagulated with diathermy. At the time I thought that I had clipped the right anterior cerebral artery just proximal to the communicating artery, and I

anticipated a good recovery, for the preoperative arteriograms had indicated that the distal part of the right anterior cerebral artery would be well supplied through the communicating artery. However, although the patient's physical convalescence was smooth, he has since operation exhibited profound disturbances of recent memory and of initiative. For several months after operation he used to walk around the ward in a cheerful and cooperative state, and without any motor disorder. He would readily enter into conversation, and he 
could promptly and accurately recall events from his past life, as well as describe his home surroundings. But he was disorientated as regards the present and he could not remember things that had happened or been told to him a few minutes earlier. He read voraciously, but without remembering a few minutes later what he had read, and he wrote long newsy letters home, full of imaginary events and doings. After some months some improvement was noted, but, although he had then returned to work on his parent's farm, he has still to be directed and supervised, and his recent memory is still very poor.

We were naturally concerned with this unexpectedly poor result, and so several weeks after operation we repeated the percutaneous arteriogram (Fig. 27). The new views showed, first that the occluding clips were in the midline in the position of the anterior communicating artery ; and secondly that the trunks of the anterior cerebral arteries in this vicinity were occluded. Instead, distal to this site of occlusion the blood-flow through each anterior cerebral artery was being maintained by an anastomotic circulation coursing over the superior margin of the frontal lobe from the

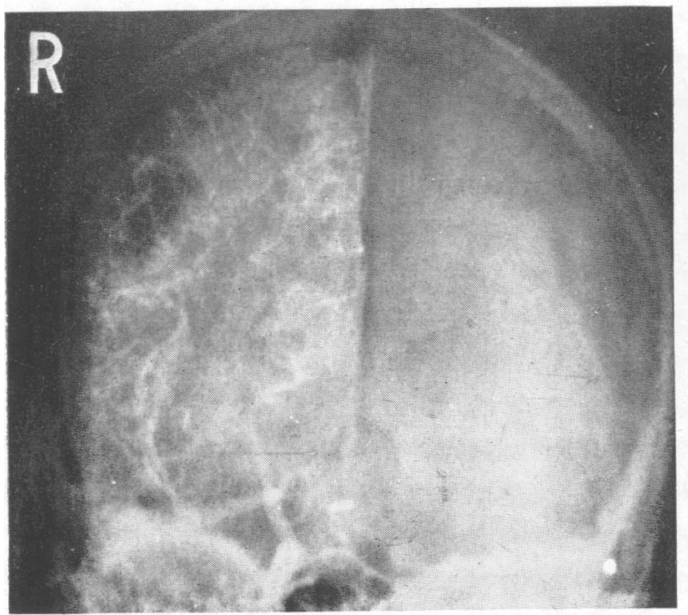

excised, describe a postoperative mental state similar to that observed in my patient. It is possible that in their operative manipulations they too occluded both anterior cerebral arteries in the vicinity of the communicating artery.

(3) Aneurysms of the Distal Portion of the Artery. - There were four examples, and they were treated surgically with two deaths and two good recoveries. Although our experience is still scanty, our observations suggest that these aneurysms are often associated with a massive intracerebral haemorrhage (all four cases had haemorrhages within one or both frontal lobes), and that in treating these cases it is important that these haemorrhages should be evacuated. Consequently an intracranial attack is called for. As regards local measures, these aneurysms can often be safely treated either by clipping the anterior cerebral artery immediately proximal to the aneurysm or by trapping the aneurysm between clips applied to the artery on either side of it.

In arteriograms these aneurysms show up as shadows on the anterior cerebral artery, usually at a point of branching in its pericallosal course (Figs. 28, 30, and 31). If there is a massive intra-

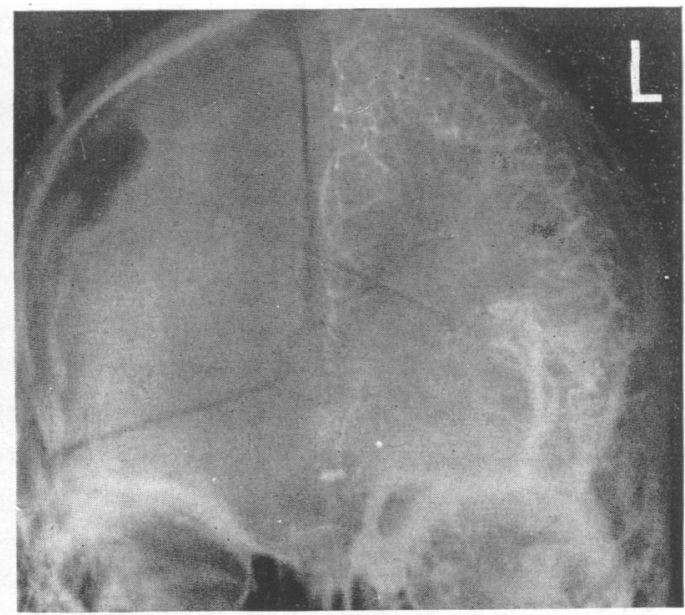

FIG. 27.-Postoperative arteriograms demonstrate silver clip in position of anterior communicating artery, and also show absence of filling of the two anterior cerebral arteries in this vicinity. Instead, the distal part of each anterior cerebral artery is being supplied by a collateral circulation from its corresponding middle cerebral artery.

corresponding middle cerebral artery. In retrospect it seems likely that the aneurysm was situated on the anterior communicating artery rather than on the right anterior cerebral artery, and that the anterior communicating artery was the vessel which was clipped with perhaps the two anterior cerebral arteries at either end of it. Elvidge and Feindel (1950) in reporting the case of aneurysm of the anterior communicating artery which they had cerebral haemorrhage confined to one frontal lobe, the aneurysm with the adjacent portion of the anterior cerebral artery will usually be displaced to the opposite side, but if bilateral frontal lobe haemorrhages are present (as in one of our cases) the aneurysm may still be in the midline. If there is a free collateral circulation through the anterior communicating artery the aneurysm may be outlined by injection of either carotid artery. 


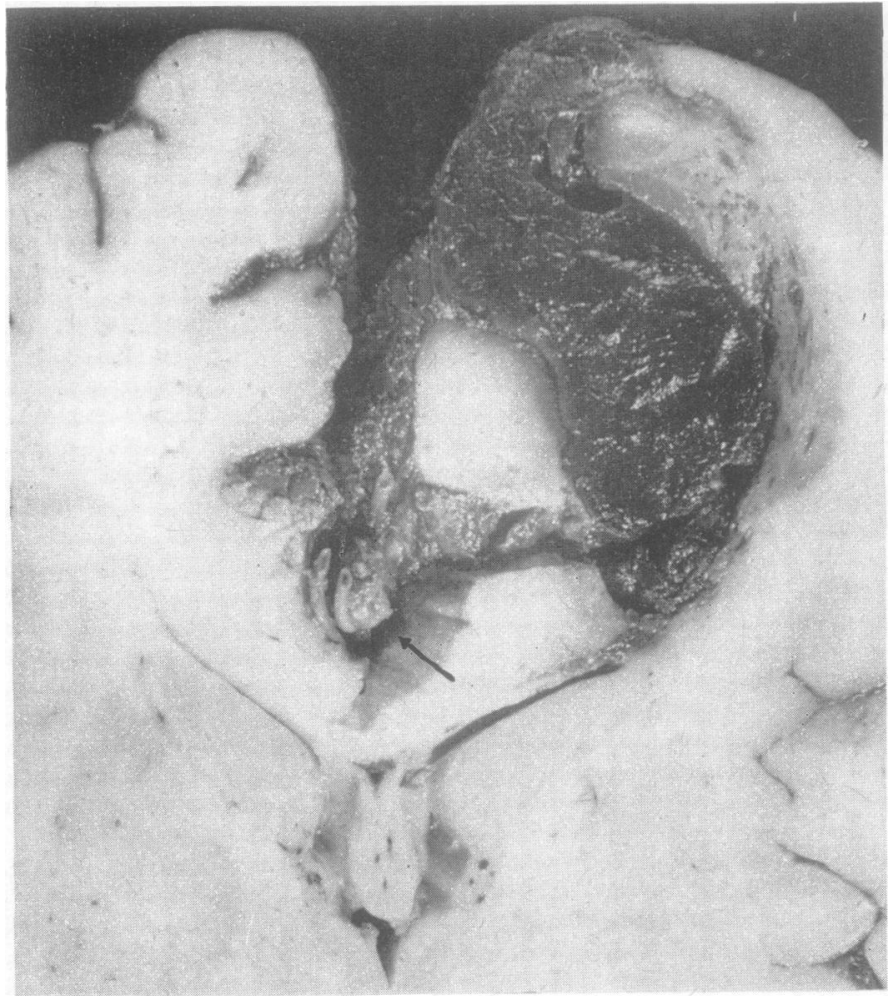

FIG. 28.-Arteriogram demonstrating aneu- $\frac{0}{2} \frac{2}{\infty}$ rysm arising from anterior cerebral $\overrightarrow{0}$ artery at origin of its fronto-polar $\frac{\bar{Q}}{2} \overrightarrow{0}$ branch. The A.P. view shows that the $\stackrel{P}{\rightarrow}$ aneurysm and the anterior cerebral artery are displaced slightly across the midline suggesting an intracerebral haemorrhage.

FIG. 29.-Photograph of coronal section of brain viewed from behind to show an aneurysm (arrow) of the right anterior cerebral artery associated with a haemorrhage within the frontal lobe.

FiG. 29 

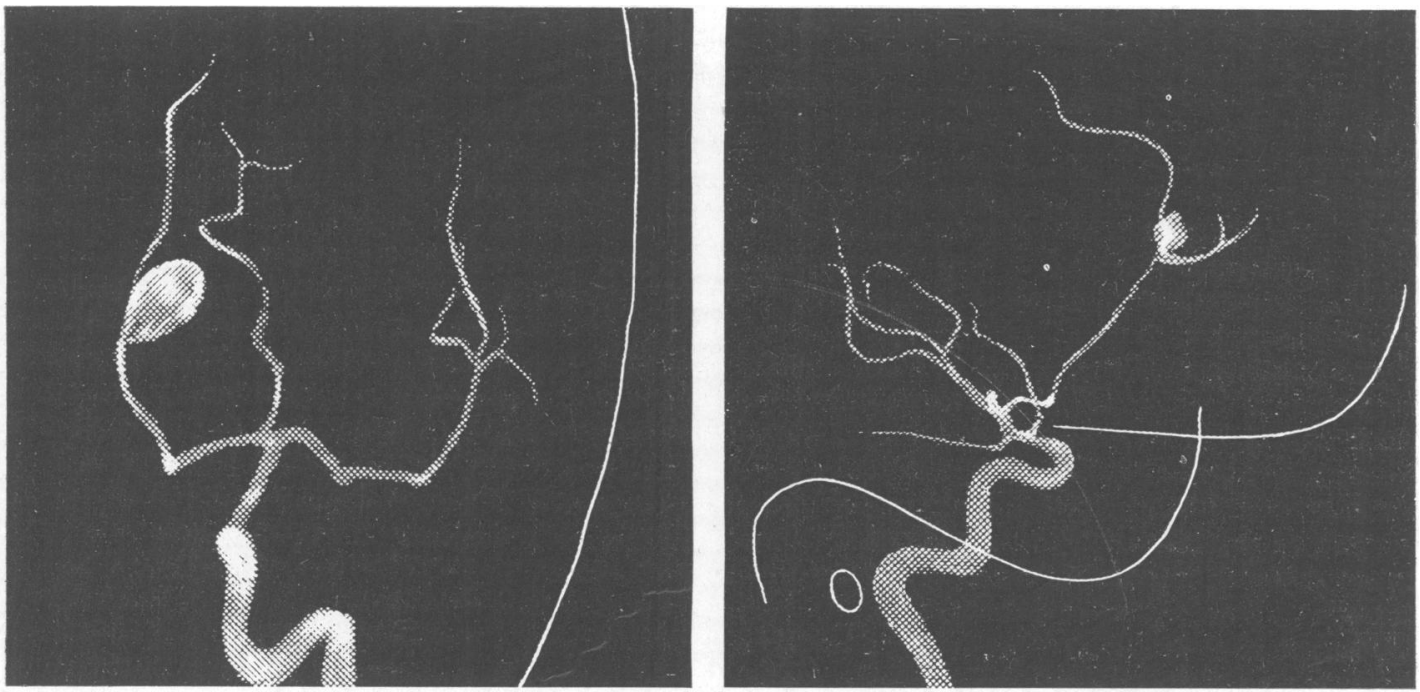

FIG. 30
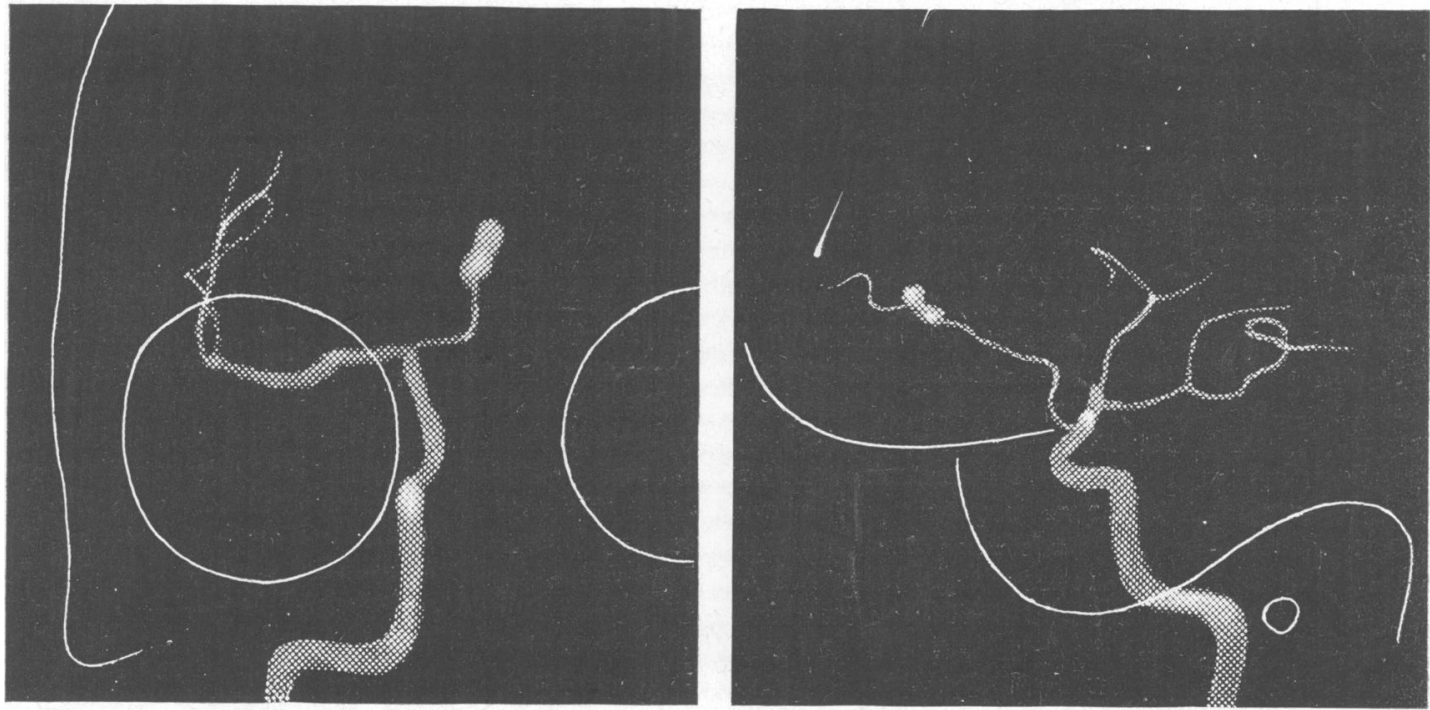

FIG. 31

FIGs. 30 and 31.-Tracings of arteriograms of other aneurysms of the distal portion of the anterior cerebral artery.

The first case ended fatally, but taught us an important lesson. The aneurysm was clearly shown by arteriography of the right carotid artery, but not of the left and there was also a shift of the anterior cerebral arteries to the left side (Fig. 28). The right common carotid artery was thereupon ligated, but the patient failed to rally, and at necropsy a large intracerebral haemorrhage was found within the right frontal lobe, the result of bleeding from the aneurysm (Fig. 29). There was no blood within the ventricles and little blood in the basal cisterns. The appearances of the brain suggested that raised intracranial pressure secondary to a large space-occupying lesion had been the cause of death, and that the proper way to have treated this case would have been by an intracranial attack.

In the two successful cases the presence of such a space-occupying lesion was recognized from the shift of the anterior cerebral artery in the arterio- 
grams, and both cases were then submitted to a frontal craniotomy without resort to carotid ligation. In each instance the brain was "tight" when the dura was opened, but slackened after the convexity of the frontal lobe had been incised and the clot evacuated. In the first of these cases, one with a large aneurysm nearly an inch in diameter, there was so much scar tissue around the anterior cerebral artery in front of the aneurysm that $I$ was not able to define the artery in this part of its course. The aneurysm was therefore buttressed with hammered muscle on the side which faced the massive intracerebral clot, while the anterior cerebral artery was exposed and clipped immediately proximal to the communicating artery. Theoretically the aneurysm should still be supplied with blood through the communicating artery, but post-operative arteriograms have not demonstrated this filling. The patient has now been followed for more than a year, and although he exhibits some impairment of initiation, he works on his own farm and has no motor disability. In the second successful case (Fig. 30) the cerebral artery was clipped on either side of the aneurysm, and the patient made an excellent recovery without any sign of motor paralysis in the leg. The post-operative arteriogram did not show filling of the anterior cerebral artery beyond the clips:

The remaining case was not really a fair test for any therapeutic procedure because the patient, although only 38 years old, had been under medical treatment for some months on account of arterial hypertension, and had a blood pressure of 215/150. Still she had had two definite attacks of subarachnoid bleeding in a month and had been unconscious since the second attack two weeks previously. The arteriograms disclosed the aneurysm, but did not fill the trunk of the anterior cerebral artery beyond it (Fig. 31). Also there was no shift, although at the subsequent craniotomy a moderatesized haemorrhage was sucked out of the frontal lobe. At operation the aneurysm was exposed and wrapped with muscle, but following operation the patient remained mute and apathetic until her death six weeks later. At necropsy two small haemorrhages were found, one in the callosal gyrus on each side, while each anterior cerebral artery was thrombosed in its pericallosal course. This particular patient was suffering more from the general and cerebral effects of hypertensive vascular disease than from those of subarachnoid haemorrhage.

\section{Aneurysms of the Vertebral, Basilar, and Posterior Cerebral Arteries}

Most leaking aneurysms are connected with the anterior half of the circle of Willis. Richardson and Hyland (1941) in a post-mortem study of 27 ruptured aneurysms found only three ruptured aneurysms on the vertebral-basilar arterial system, while Magee (1943) in 43 ruptured aneurysms noted only nine on this system. Thus only a minority of leaking aneurysms occur on the posterior part of the circle of Willis, and very few reports of operations upon them appear in the literature. In 1944, Dandy stated: "I know of no successful outcome for operative attack upon an aneurysm in the posterior cranial fossa, but for those on the vertebral and posterior inferior cerebellar arteries, which afford good exposure, cures will certainly come in time". Dandy also envisaged that aneurysms on the posterior cerebral artery mighi be attacked by resecting the occipital lobe and then clipping or thrombosing the artery on either side of its neck. German, in 1938, in a report of a single line stated that he had done this and that his patient had recovered. Since Dandy's monograph appeared Schwartz (1948) has recorded a case in which an aneurysm on a small artery in the cerebello-pontine angle was successfully treated by clipping or trapping.

No example of an aneurysm of the vertebralbasilar arterial system was recognized during life in the 69 consecutive cases of subarachnoid haemorrhage from which my 50 cases of intracranial aneurysm (all on the carotid arterial system), were collected. It is possible that there were several instances in the 14 cases in which a bleeding lesion was not demonstrated by bilateral carotid arteriography, for, in one of the two fatal cases in this subgroup, a ruptured aneurysm was found at necropsy at the bifurcation of the basilar artery. Vertebral arteriography, using King's (1942) method, was performed in only three of the cases, in each instance with normal findings, and all three patients survived. Had vertebral arteriography been performed as a routine in the nine remaining cases in which carotid arteriography was normal, it is possible that other instances of posterior aneurysm might have been disclosed. Alternatively some of the cases might have been examples of aneurysms in connexion with the anterior half of the circle of Willis, which had not filled with contrast medium either because the neck of the aneurysm was narrow or because the aneurysm had already thrombosed. Certainly Jefferson (1937), Krayenbühl (1941), Frankel (1950), and others have had experience of intracranial aneurysms that were not disclosed by arteriography, but were later found at operation. Hermann, Obrador, and Dott (1937) postulated thrombosis of the aneurysm to explain cases with normal arteriographic findings after subarachnoid haemorrhage, and we feel that, after a recent bout 
of subarachnoid bleeding, the finding of normal carotid arteriograms in association with a clinical state that is improving suggests a good prognosis.

However, I have recently had a case in which an aneurysm was located on the posterior cerebral artery and was apparently successfully treated by ligation of the vertebral artery. The patient, a woman of 58 years, had three weeks earlier experienced a sudden headache followed immediately by amnesia for 10 hours with persistent headache on regaining consciousness. Ten days later she awoke with a complete palsy of the third cranial nerve on the right side. Suspecting an aneurysm of the right internal carotid artery, we obtained a right carotid arteriogram, but the appearances were normal. This was followed by arteriography of the right vertebral artery performed according to the method of Radner (1947 and 1949), and the new arteriograms disclosed an aneurysm in the position of the posterior cerebral artery close to its origin, and presumably therefore in relation to the posterior communicating artery (Fig. 32). It was also noted that the right vertebral arteriogram had shown up vessels on the right side of the cerebellum and in the right occipital lobes, but not on the left side. This was thought to indicate that the left vertebral artery was sizeable, and that the blood stream from the two vertebral arteries remained separate as they passed together up the basilar artery.

Consideration of treatment then arose. The method suggested by Dandy of resecting the right occipital lobe in order to gain access to the posterior cerebral artery would have produced a complete homonymous hemianopia, and was dismissed as too drastic. As an alternative it was felt that occlusion of the right vertebral artery would diminish the pressure and the blood-flow within the affected vessel, and so lessen the risk of further bleeding. Therefore, under local analgesia, the right vertebral artery was exposed low in the neck as it came off the first part of the subclavian artery. It was first occluded with a Crile's clamp for a period of 35 minutes and then, as there were no untoward effects, it was tied in continuity with a heavy silk ligature. The patient recovered without any anoxic symptoms, and when she was seen again three months later, her cranial nerve palsy was recovering.

Apart from German's case, about which there are no published details, this is the only case I am aware of, in which an aneurysm of the posterior cerebral artery has been treated surgically. Krayenbühl, in 1941, published particulars of a similar case also with a unilateral third nerve palsy in which by means of vertebral arteriography (Moniz method) he had demonstrated an aneurysm in the same situation on the posterior cerebral artery. The aneurysm, however, was not treated surgically. The procedure of vertebral ligation should be approached warily. Dandy (1944) stated that he had ligated one vertebral artery " perhaps 20 times without any untoward effect", and also quoted Alexander who, in 1882, had reported having ligated with impunity one or even both vertebral arteries as a treatment for epilepsy. However, recently both Guthkelch (1949) and French and Haines (1950) have reported cases where a fatality followed ligation of one vertebral artery. Dandy also gave his personal experience of a case in which, after having occluded one vertebral artery, he prepared the second for ligation. "Before the vessel was ligated it was compressed with the forceps for perhaps two seconds and then released. Death was immediate. Pulse and respiration ceased, and despite release of the compression and artificial respiration there was no return of pulse or breathing. There could be no more speedy death."

\section{DISCUSSION}

Statistics are not available by which one can precisely measure the mortality rate that would have occurred in our 50 cases of leaking aneurysm had they not been treated surgically. There are, however, certain pointers. First, in the ordinary run of cases of spontaneous subarachnoid haemorrhage the mortality rate varies between 50 and $60 \%$ with a satisfactory recovery rate of between 16 and $30 \%$ (Table I). Secondly, in cases that develop recurrent bleeding the mortality rises even higher (Table II). And thirdly, when cases of subarachnoid haemorrhage die and come to necropsy, ruptured aneurysms can be demonstrated in about 75 to 80\% (Richardson and Hyland, 1941 ; Magee, 1943 ; Hyland, 1950). As my series contained so many recurrent cases, I think it can be conceded that the mortality likely in our 50 cases of aneurysm, had they continued on conservative treatment, would have been even higher than the average figures mentioned above.

Instead, my series of operated cases shows a mortality rate of $18 \%$ associated with a satisfactory recovery rate of $66 \%$ and a total recovery rate of $82 \%$. In addition, five of the disabled female patients, although exhibiting an appreciable degree of paralysis, are still able to look after their homes with little or no assistance from others, and these, if added to the good recoveries, make a useful recovery rate of $76 \%$. Only three of the surviving patients (6\% of total group) are severely disabled. Furthermore, of the 24 patients in my series, whose ages were 40 years or less, only two died (mortality rate $8.5 \%$ ), whereas in a comparable group of 141 patients in the same age groups with spontaneous 
Fig. 32.-Tracings of arteriogram of vertebral artery showing an aneurysm of the posterior cerebral artery.
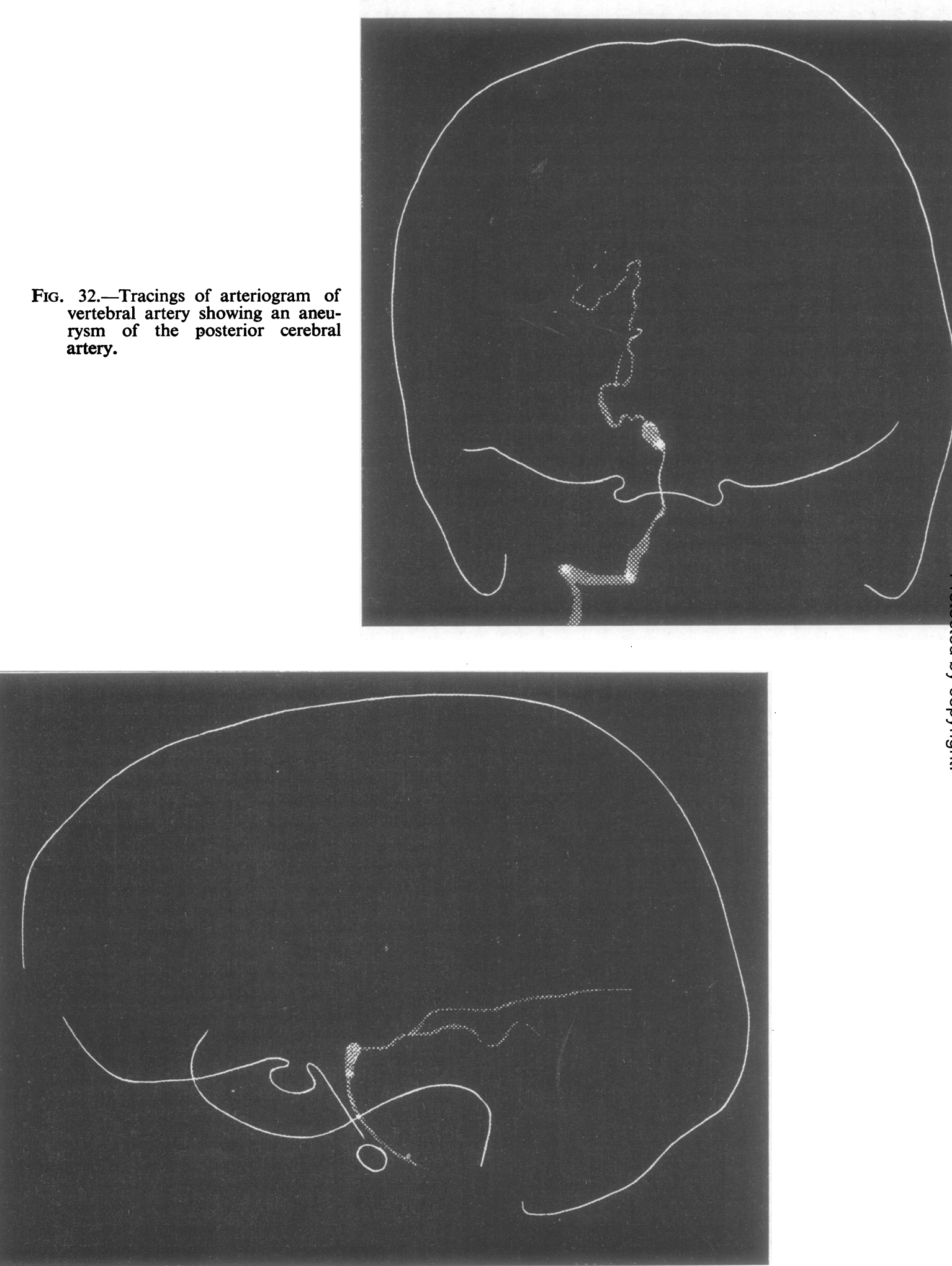

흔.

을 $\overrightarrow{0}$

○ 
TABLE I

MORTALITY AND RECOVERY RATES* WITH CONSERVATIVE TREATMENT IN SPONTANEOUS SUBARACHNOID HAEMORRHAGE

\begin{tabular}{l|c|c|c|c|c}
\hline & $\begin{array}{c}\text { Birmingham } \\
\text { Hospitals, U.K. } \\
\text { (Taylor and } \\
\text { Whitfield, 1936) }\end{array}$ & $\begin{array}{c}\text { Buffalo General } \\
\text { Hospital, U.S.A. } \\
\text { (Hamby, 1948) }\end{array}$ & $\begin{array}{c}\text { Dunedin Hospital } \\
\text { N.Z. (Author's } \\
\text { data, 1943-47) }\end{array}$ & $\begin{array}{c}\text { Toronto General } \\
\text { Hospital, Canada } \\
\text { (Hyland, 1950) }\end{array}$ & $\begin{array}{c}\text { Ministry of } \\
\text { Pensions, U.K. } \\
\text { (Magee, 1943) }\end{array}$ \\
\hline \begin{tabular}{l} 
Number of patients \\
\hline $\begin{array}{c}\text { Died while under } \\
\text { treatment (\%) }\end{array}$
\end{tabular} & 81 & 130 & 31 & 191 & 150 \\
\hline $\begin{array}{l}\text { Recovered satisfac- } \\
\text { torily (\%) }\end{array}$ & ? Under 20 & 16 & 63 & 53 & 56 \\
\hline
\end{tabular}

* The statistics of Wolf, Goodall, and Wolff (1945) relating to the New York Hospital are more favourable than those listed above, but have been excluded because some selection evidently occurred in their case-material.

TABLE II

PROGNOSIS WITH CONSERVATIVE MANAGEMENT OF PATIENTS IN INITIAL AND RECURRENT ATTACKS OF SUBARACHNOID HAEMORRHAGE

\begin{tabular}{|c|c|c|c|}
\hline & $\begin{array}{l}\text { Buffalo General } \\
\text { Hospital, U.S.A. } \\
\text { (Hamby, 1948) }\end{array}$ & $\begin{array}{l}\text { Dunedin Hospital, } \\
\text { New Zealand } \\
\text { (Author's data, } \\
1943-47 \text { ) }\end{array}$ & $\begin{array}{l}\text { Ministry of } \\
\text { Pensions, } \\
\text { United Kingdom } \\
\text { (Magee, 1943) }\end{array}$ \\
\hline Number of patients observed in initial attack & 98 & 31 & 150 \\
\hline Proportion who died in initial attack & $? 42 \%$ & $23 \%$ & $35 \%$ \\
\hline \multirow{2}{*}{$\begin{array}{l}\text { Number of above patients who survived initial attack } \\
\text { Proportion of these who developed a recurrent attack }\end{array}$} & - & 24 & 98 \\
\hline & - & $46 \%$ & $51 \%$ \\
\hline $\begin{array}{c}\text { Number of patients who developed a recurrent attack } \\
\text { while under observation } \quad \ldots\end{array}$ & 61 & 11 & 50 \\
\hline Proportion of these who died in recurrent attack .. & $65 \%$ & $91 \%$ & $64 \%$ \\
\hline
\end{tabular}

subarachnoid haemorrhage treated conservatively, Magee (1943) found that 79 died (mortality rate, $56 \%$ ). This improvement in prospects for patients treated surgically has led us to the conclusion that surgical treatment should become a routine measure in the treatment of subarachnoid haemorrhage when the vascular abnormality or aneurysm can be located by arteriography.

My patients have now been followed up for periods ranging between six months and four years, and so far only one instance of recurrent haemorrhage has been reported. This recurrence occurred within four weeks of operation and is discussed in an earlier section, while the case itself is included in the total of fatal cases. It is possible that recurrent bleeding may yet arise in other cases, either from the aneurysm which was treated or from a fresh aneurysm, but the proportion of recurrences is not likely to be large. In contrast Hyland (1950) records that of 67 patients who were traced for an average period of 10 years following recovery under a conservative regime, recurrent haemorrhage was found to have occurred in about $20 \%$.

Nine patients in the series died, and eight recovered with an appreciable disability. In the light of later experience these results might have been improved, had some of the patients been handled differently. Certainly two patients died primarily because of space-occupying effects of large intracerebral clots which should have been removed. One patient died of infarction of both frontal lobes because we had unwittingly tied an internal carotid artery which was supplying both anterior cerebral arteries. Further, in three cases the application of a silver clip to the neck of the sac caused the sac to burst and, although the haemorrhage was controlled at the time by other means, all three cases subsequently developed spreading thrombosis and two of them died. Thus, although we had some success with this method we have now become very chary of applying it. The outcome in all these cases just cited might 
have been bettered, but in those other cases which died from laceration and infarction of the adjacent brain from intracerebral haemorrhage death might not have been preventable.

The question then arises as to how soon after an attack of subarachnoid haemorrhage should one wait before beginning surgical investigations. Our policy now is to do this as soon as arrangements can conveniently be made, no matter whether the patient has had one or several bouts of bleeding or whether bleeding is still in progress or has stopped. If a patient is still actively bleeding, and his transfer involves long road or air transport, we prefer to wait 24 hours or so until the fresh bleeding ceases, before transporting him to the neurosurgical centre.

There is in subarachnoid haemorrhage a marked tendency towards recurrence of bleeding. Indeed of those patients who survive their first attack half will develop a recurrence of bleeding (Table II), and, as Magee (1943) has also shown, the incidence of these recurrences reaches its peak in the third and fourth weeks after the initial attack, at a period when the patient seems to be progressing favourably (Table III). It is therefore wise not to procrastinate

TABLE III

LATENT PERIOD BEFORE RECURRENCE IN PATIENTS SURVIVING INITIAL ATTACK OF SUBARACHNOID HAEMORRHAGE*

(1) Total cases of subarachnoid haemorrhage . . 150

(2) Died of initial attack ... $\quad . \quad \ldots . .42$

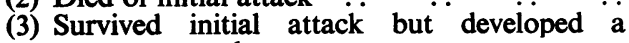
recurrent attack ..

50

Analysis of Subgroup (3)

\begin{tabular}{c|r|r}
\hline $\begin{array}{c}\text { Period within which } \\
\text { bleeding recurred } \\
\text { (Weeks) }\end{array}$ & Cases & Died \\
\hline 1 & 4 & 3 \\
2 & 9 & 5 \\
3 & 12 & 8 \\
4 & 7 & 7 \\
5 & 4 & 1 \\
6 & 4 & 2 \\
7 & 0 & 0 \\
8 & 7 & 5 \\
\hline Over 8 & 50 & 32 \\
\hline
\end{tabular}

* From Magee, 1943.

with the decision to perform arteriography. We learnt this partly by experiences additional to those already mentioned. During the period when we were collecting our first 12 cases, our medical colleagues asked us to see in consultation five patients admitted to their wards shortly after their first attack. By the time we saw them they seemed to be settling nicely, and so we decided to leave them alone. But to our later regret no fewer than three of them subsequently developed a second attack while still in hospital and all three succumbed rapidly before we could be advised. At necropsy each case exhibited what would have been a surgically remediable lesion. This experience greatly influenced our attitude to subarachnoid haemorrhage, and subsequently we have regarded all cases of this condition as surgical emergencies. In only two cases of subarachnoid haemorrhage referred to us since then have we failed to undertake surgical treatment, and then only because the patient was moribund and died before we could begin. The temptation to leave a patient alone because he appears to be settling spontaneously is clearly a dangerous policy to adopt.

Not all cases of subarachnoid haemorrhage are due to intracranial aneurysms, although the majority are. As has already been pointed out, during the period in which we collected these 50 cases of aneurysm, we also saw 19 other cases with subarachnoid haemorrhage, four of which were found to be due to leaking arteriovenous malformations, one to a tiny perforation on a major vessel without aneurysmal formation, while in the remaining 14 cases no arteriographic abnormalities were seen. The four cases of leaking arteriovenous malformation as well as the one with a perforation were allo operated on with recovery, while of the 14 cases in which no arteriographic abnormality was seen and hence no definite surgical procedure carried out, $\varnothing$ only two died. The total mortality for the wholeo group of 69 cases was 11 deaths, or $16 \%$. Surgery, $\overrightarrow{0}$ therefore, has a place in the treatment of sub- 0 arachnoid haemorrhage as a whole, and not merely in the cases due to aneurysm.

The surgery of intracranial aneurysms is still in its infancy and we have come a long way since Harvey Cushing (1923) described cerebral aneurysm as " a lesion having such remote surgical bearings". Further developments are likely. The demand for surgery will probably grow appreciably, for subarachnoid haemorrhage is relatively common. In New Zealand we arrived at statistics which suggest that in that country one case of subarachnoid haemorrhage occurs per 10,000 of population each year (Falconer, 1950), while elsewhere pathologists have observed an incidence of cerebral aneurysms in from 0.5 to $1.5 \%$ of persons who come to necropsy (Richardson and Hyland, 1941). The field for surgery is thus a large one. It is also a rewarding one, for the patients are often young and active subjects whose misfortune is merely that they have "a length of defective tubing" in their blood vessels, which, if repaired, will ensure their full and active lives once more. They are a more rewarding group than are the intracranial tumours with which 
neurosurgeons so largely concern themselves. We have demonstrated that they can be benefited surgically, but the methods which we applied may with further experience be improved upon. Other surgeons doubtless will try other measures, and time will decide their permanence and worth.

\section{SUMMARY}

A series of 50 consecutive cases of leaking intracranial aneurysm was treated surgically by carotid ligation or an intracranial exposure, or by a combination of these procedures, with nine deaths. Thirty-three patients made good recoveries; five patients, although disabled, are leading economically useful lives, and three patients are severely disabled. These figures are compared with the mortality rate of between 50 and $60 \%$ and the satisfactory recovery rate of between 16 and $30 \%$ which follows conservative management in the ordinary run of cases of subarachnoid haemorrhage. Probably the mortality rate in the surgical series, had they not been submitted to operation, would have been higher than these figures.

It is felt that all cases of subarachnoid haemorrhage should be submitted as soon as possible to carotid arteriography, and that those cases in which an aneurysm or arteriovenous malformation is revealed should be operated on forthwith.

The treatment of choice for aneurysms of the intracranial internal carotid artery is felt to be stage-ligation of the common carotid artery, followed later by ligation of the internal carotid artery in the neck and by clipping of the intracranial internal carotid above the neck of the aneurysm and below the neck of Willis (i.e. trapping of the aneurysm).

The treatment of choice for aneurysms at the bifurcation of the internal carotid artery is a direct intracranial exposure and either wrapping the aneurysm with muscle or clipping its neck. This may be preceded by a preliminary carotid ligation.

The treatment of choice for aneurysms of the middle cerebral artery or of the proximal part of the anterior cerebral artery including the communicating artery is also by a direct intracranial exposure with wrapping of muscle around the aneurysm. Clipping the neck is sometimes efficacious, but carries the risk of operatively rupturing the aneurysm. These aneurysms are often associated with haemorrhage into the adjacent frontal or temporal lobes, and such intracerebral clots should be evacuated. In some cases a preliminary carotid ligation is required.

For aneurysms of the anterior cerebral artery distal to the communicating artery, trapping the aneurysm between clips or ligatures placed on the parent artery is felt to be a practical method. Carotid ligation is not required.

A single case of aneurysm of the posterior cerebral artery causing both subarachnoid haemorrhage and one isolated third nerve palsy is reported. It was treated by unilateral vertebral artery ligation.

It is felt that spontaneous subarachnoid haemorrhage is an emergency which calls for surgical handling.

My thanks are due to the various physicians and surgeons who have entrusted their patients to me, and in particular to Professor F. G. Bell, F.R.C.S., Dr. J. A. D. Iverach, and Dr. R. H. Q. Baxter, who encouraged me in my first operations. My former associate, Mr. Anthony James, F.R.A.C.S., now head of the Dunedin Neurosurgical Unit, collaborated in the operative work, and Dr. A. C. Begg and Mr. M. Allen of the $x$-ray department of the Dunedin Hospital contributed in the arteriographic studies. Mr. James also furnished the operation sketches, and Miss Treadgold, of the Department of Medical Illustration, Guy's Hospital, made the arteriographic tracings. I am indebted to Sir Charles Symonds, K.B.E., for helpful criticisms regarding the assembling of this paper.

\section{REFERENCES}

Albright, F. (1929). Bull. Johns Hopk. Hosp., 44, 215. Cone, W. Quoted by Russel (1939).

Critchley, M. (1930). Brain, 53, 120.

Cushing, H. (1923). Guy's Hosp. Rep., 73, 159.

Dandy, W. E. (1938). Ann. Surg., 107, 654. (1944). "Intracranial Arterial Aneurysms." Ithaca, New York State.

Dott, N. M. (1933). Trans. med.-chir. Soc. Edinb., 112, 219.

(1948). Personal communication.

Elvidge, A. R., and Feindel, W. H. (1950). J. Neurosurg., 7, 13.

Falconer, M. A. (1950). Brit. med. J., 1, 809.

Fincher, W. J. (1939). Yale J. Biol. Med., 11, 423.

Frankel, K. (1950). Arch. Neurol. Psychiat., Chicago, 63, 195.

French, L. A., and Haines, G. L. (1950). J. Neurosurg., 7, 156.

German, W. J. (1938). Zbl. Neurochir., 3, 352.

Guthkelch, A. N. (1949). Brit. J. Surg., 37, 107.

Hamby, W. B. (1948). J. Amer. med. Ass., 136, 522.

Hermann, K., Obrador, S., and Dott, N. M. (1937). Lisboa méd., 14, 782.

Hyland, H. H. (1950). Arch. Neurol. Psychiat., Chicago, 63,61 .

Jaeger, R. (1950). J. Amer. med. Ass., 142, 304.

Jefferson, G. (1937). Brain, 60, 444. (1947). Proc. roy. Soc. Med., 40, 419.

King, A. B. (1942). Bull. Johns Hopk. Hosp., 70, 81.

Krayenbühl, H. (1941). Schweiz. Arch. Neurol. Psychiat., 47, 155.

(1946). Schweiz. med. Wschr., 76, 908.

List, C. F., and Hodges, F. J. (1946). J. Neurosurg., $3,25$.

McConnell, A. A. (1937). Z Zbl. Neurochir., 2, 269. 
Magee, C. G. (1943). Lancet, 2, 497.

Matson, D. D., and Woodhall, B. (1948). J. Neurosurg., 5, 567.

Moniz, E. (1933). Rev. oto-neuro-ophtal., 11, 746. (1934). "L'angiographie cérébrale." Paris.

Murphy, J. P. (1949). Med. Ann. Distr. Columbia, $18,119$.

Radner, S. (1947). Acta radiol., Stockh., 28, 838. (1949). Ibid., 31, 152.

Richardson, J. C., and Hyland, H. H. (1941). Medicine, Baltimore, 20, 1.

Robertson, E. G. (1949). Brain, 72, 150.

Rogers, L. (1944). Brit. J. Surg., 32, 309. (1947). Ibid, 35, 43.

(1949). Lancet, 1, 949.
Russel, C. K. (1939). Trans. Amer. neurol. Ass., 65, 130.

Schorstein, J. (1940). Brit. J. Surg., 28, 50.

Schwartz, H. G. (1948). J. Neurosurg., 5, 312.

Sugar, O., and Tinsley, M. (1948). Arch. Neurol. Psychiat., Chicago, 60, 81.

Swain, R. D. (1948). Surg. Clin. N. Amer., 28, 396.

Sweet, W. H., Sarnoff, S. J., and Bakay, L. (1950). Surg. Gynec. Obstet., 90, 327.

Symonds, C. P. (1923). Guy's Hosp. Rep., 73, 139. (1924). Quart. J. Med., 18, 93.

Taylor, A. B., and Whitfield, A. G. W. (1936). Ibid, n.s., 5, 461 .

Tönnis, W. (1936). Zbl. Neurochir., 1, 39.

Wolf, G. A., Goodell, H., and Wolff, H. G. (1945). J. Amer. med. Ass., 129, 715.

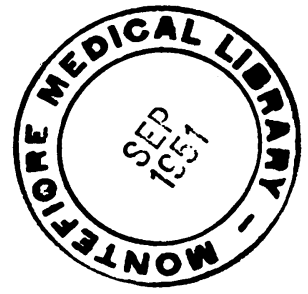

